ARTICLE

\title{
The long non-coding RNA MIR31HG regulates the senescence associated secretory phenotype
}

\author{
Marta Montes (1) ${ }^{1 凶}$, Michal Lubas ${ }^{1}$, Frederic S. Arendrup (10 ${ }^{1}$, Bettina Mentz ${ }^{1}$, Neha Rohatgi ${ }^{2}$, Sarunas Tumas ${ }^{1,4}$, \\ Lea M. Harder ${ }^{3}$, Anders J. Skanderup (10 ${ }^{2}$, Jens S. Andersen $~^{3}{ }^{3} \&$ Anders H. Lund (10 ${ }^{1 凶}$
}

Oncogene-induced senescence provides a barrier against malignant transformation. However, it can also promote cancer through the secretion of a plethora of factors released by senescent cells, called the senescence associated secretory phenotype (SASP). We have previously shown that in proliferating cells, nuclear IncRNA MIR31HG inhibits p16/CDKN2A expression through interaction with polycomb repressor complexes and that during BRAFinduced senescence, MIR31HG is overexpressed and translocates to the cytoplasm. Here, we show that MIR31HG regulates the expression and secretion of a subset of SASP components during BRAF-induced senescence. The SASP secreted from senescent cells depleted for MIR31HG fails to induce paracrine invasion without affecting the growth inhibitory effect. Mechanistically, MIR31HG interacts with YBX1 facilitating its phosphorylation at serine 102 $\left(\mathrm{p}-\mathrm{YBX}^{\mathrm{S} 102}\right.$ ) by the kinase RSK. $\mathrm{p}-\mathrm{YBX}{ }^{\mathrm{S} 102}$ induces IL1A translation which activates the transcription of the other SASP mRNAs. Our results suggest a dual role for MIR31HG in senescence depending on its localization and points to the IncRNA as a potential therapeutic target in the treatment of senescence-related pathologies.

\footnotetext{
${ }^{1}$ Biotech Research and Innovation Centre, University of Copenhagen, Copenhagen, Denmark. ${ }^{2}$ Genome Institute of Singapore, Agency for Science, Technology and Research (A*STAR), Singapore, Singapore. ${ }^{3}$ Department of Biochemistry and Molecular Biology, University of Southern Denmark, Odense, Denmark. ${ }^{4}$ Present address: Novo Nordisk Foundation Center for Biosustainability, Technical University of Denmark, Lyngby, Denmark.

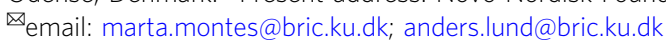


C ellular senescence is an irreversible state of growth arrest that can be driven by several stimuli including telomere shortening due to extensive replication, DNA damage, oxidative stress or oncogene overexpression ${ }^{1,2}$. In addition, it has been recently shown that senescence can play a role in differentiation and tissue regeneration ${ }^{3,4}$. Oncogene-induced senescence (OIS) was firstly reported by Serrano et al. ${ }^{5}$ when they observed that expressing an oncogenic form of Ras in primary fibroblastinduced senescence. Later work demonstrated that other oncogenes such as mutated BRAF promoted OIS both in vivo and in vitro ${ }^{6,7}$. OIS has been considered as a barrier to prevent tumour progression and additional mutations in tumour suppressor genes are required in order to bypass senescence to promote malignancy ${ }^{7-9}$. Senescent cells show a characteristic morphology and biochemical features such as halted proliferation, enlarged size, activation of the senescence-associated $\beta$ galactosidase, expression of cell cycle inhibitors and the presence of senescence-associated heterochromatin foci. Importantly, in several types of senescence, the cells secrete factors such as interleukins, cytokines and metalloproteases, which are part of the senescence-associated secretory phenotype (SASP) that can impact the cellular environment and homoeostasis of the neighbouring tissues ${ }^{10-12}$. The downstream effects of the SASP can be beneficial or detrimental depending on the tissue context ${ }^{13,14}$. It has been shown to prevent cancer progression by reinforcing autocrine senescence, inducing paracrine senescence in neighbouring cells ${ }^{11,12}$, and by inducing tissue repair and regeneration ${ }^{3,4,15}$. The SASP can also activate the immune system facilitating the clearance of damaged cells ${ }^{16,17}$. On the other hand, the SASP can promote tumorigenic processes such as angiogenesis and invasion ${ }^{10,18}$. During aging, excessive SASP secretion can induce chronic inflammation that can lead to aged-related pathologies ${ }^{19,20}$. The composition of the SASP is very variable depending on different aspects such as the senescence stimuli and the cell type ${ }^{21,22}$. Defining the composition of the secretome and identifying new regulators in each biological context is crucial to identify molecular signatures of such a complex phenotype.

Previously, the long non-coding RNA (lncRNA) TERRA has been shown to be a component of inflammatory exosomes and to modulate transcription of inflammatory cytokines in recipient cells $^{23}$ and other lncRNAs have been reported to regulate nuclear factor $\kappa B(\mathrm{NF}-\kappa \mathrm{B})$ activation and its downstream target genes $^{24-26}$. These findings raise the hypothesis that lncRNAs could act as key players in the SASP induction during senescence. A few lncRNAs have been directly linked to senescence ${ }^{27-29}$. We have previously identified the lncRNA MIR31HG to be upregulated in BRAF mediated $\mathrm{OIS}^{28}$. In proliferating cells nuclear MIR31HG represses p16/CDKN2A expression by recruiting Polycomb group complexes. Indeed, we have shown that in melanoma patients harbouring BRAF mutations, MIR31HG negatively correlates with p16/CDKN2A expression ${ }^{28}$. Upon BRAF induction MIR31HG is upregulated and translocates to the cytoplasm where we now show that it regulates the expression of a part of the SASP repertoire. MIR31HG knock-down in BRAF-induced senescent fibroblasts reduces expression and secretion of several components of the SASP. Interestingly, conditioned medium (CM) from MIR31HG-depleted senescent cells promotes paracrine senescence but fails to induce cancer cell invasion. Mechanistically, we show that MIR31HG promotes the interaction between YBX1 and the RSK kinase resulting in YBX1 phosphorylation and subsequent induction of IL1A translation. Our results unveil the role of lncRNAs in the regulation of the SASP highlighting the dual role in senescence of MIR31HG by suppressing CDKN2A expression in young cells and facilitating production of a distinct subset of SASP factors in senescent cells.

\section{Results}

MIR31HG depletion affects SASP induction during OIS. To assess the role of MIR31HG during OIS we used immortalized human fibroblasts BJ-hTERT, expressing a constitutively active form of the mouse B-RAF (V600E) that is fused to the oestrogen receptor (BJ ER:BRAF). Addition of $1 \mu \mathrm{M}$ of 4-hydroxitamoxifen (4-OHT) activates BRAF inducing OIS ${ }^{30}$. We first confirmed that MIR31HG was overexpressed in BJ ER:BRAF upon 4-OHT induction (Fig. 1a), as we previously reported for TIG3 ER:BRAF cells $^{28}$. In validation of the model, analysis of TCGA data from thyroid and colorectal cancer tumour samples, where $B R A F$ is frequently mutated, demonstrated a higher $M I R 31 H G$ expression in tumours harbouring BRAF mutations (Fig. 1b). We performed RNA sequencing in control cells and BRAF-induced senescent cells transfected with control siRNA or siRNA targeting MIR31HG. As expected, many genes were differentially expressed comparing control versus senescent cells (Fig. 1c and Supplementary Data 1). Moreover, the transcriptional profile of MIR31HG knock-down senescent cells resembled the senescent profile with several clusters of differentially expressed genes (Fig. 1c and Supplementary Data 1). Among the GO categories significantly represented on the genes downregulated in the MIR31HG knock-down conditions we found cytokine and chemokine-related pathways (Supplementary Fig. 1a). Furthermore, we observed that senescent MIR31HG-depleted cells failed to upregulate part of the main SASP components previously defined $^{13}$ (Fig. 1d and Supplementary Data 1). We validated transcriptomics data by quantitative real-time reverse transcriptase PCR (RT-qPCR) and confirmed the RNA decreased on several interleukins and chemokines such as interleukin-6 (IL6) and CXCL1, whereas other factors such as ICAM1 or IL1A were not affected (Fig. 1e). To validate our results in another cellular system, we performed RT-qPCR analysis in TIG3 ER:BRAF cell line. Depletion of MIR31HG during BRAF-induced senescence decreases the levels of the SASP RNAs (Supplementary Fig. 1b). To investigate a broader effect of MIR31HG in another senescence model, we assessed doxorubicin-induced senescence in BJ cells. As expected, cells showed senescence markers after $48 \mathrm{~h}$ treatment with $500 \mathrm{nM}$ doxorubicin as seen by a reduced cell growth (Supplementary Fig. 1c) and the presence of $\beta$ galactosidase-positive cells (Supplementary Fig. 1d). Doxorubicin induced the expression of MIR31HG and also SASP components such as IL6, IL8 or CXCL1 (Supplementary Fig. 1e). p21 mRNA was also induced consistent with decreased cell proliferation (Supplementary Fig. 1e). Interestingly, depletion of MIR31HG with two different siRNAs resulted in decreased expression of SASP components but not p21 (Supplementary Fig. 1e).

In order to analyse the composition of the SASP at the protein level, we knocked down MIR31HG in BJ ER:BRAF cells and induced senescence by $72 \mathrm{~h} 4$-OHT treatment in serum-free medium followed by mass spectrometry analysis of secreted proteins. Untreated cells transfected with control siRNA were used as control. Control senescent cells, when compared to control proliferating cells, showed differential secretion of factors (Supplementary Fig. If and Supplementary Data 2). The secretome of senescent MIR31HG knock-down cells resembled that of control senescent cells with discrete differences (Fig. 1f and Supplementary Fig. If and Supplementary Data 2). Among the less secreted proteins upon MIR31HG depletion were inflammatory SASP factors IL6 and CXCL1 (Fig. 1f and Supplementary Fig. 1f-h). The reduced secretion of these factors and other components of the SASP (IL8 and MMP3) were validated by enzyme-linked immunosorbent assay (ELISA) and western blotting using two different siRNAs for MIR31HG (Fig. $1 \mathrm{~g}$ and Supplementary Fig. 1i). Altogether our results demonstrate that MIR31HG 
a

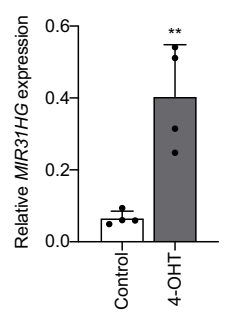

b

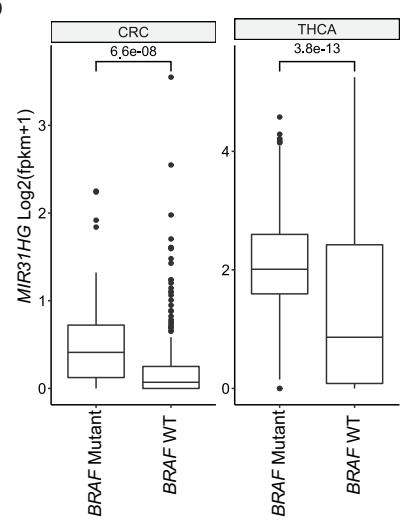

c

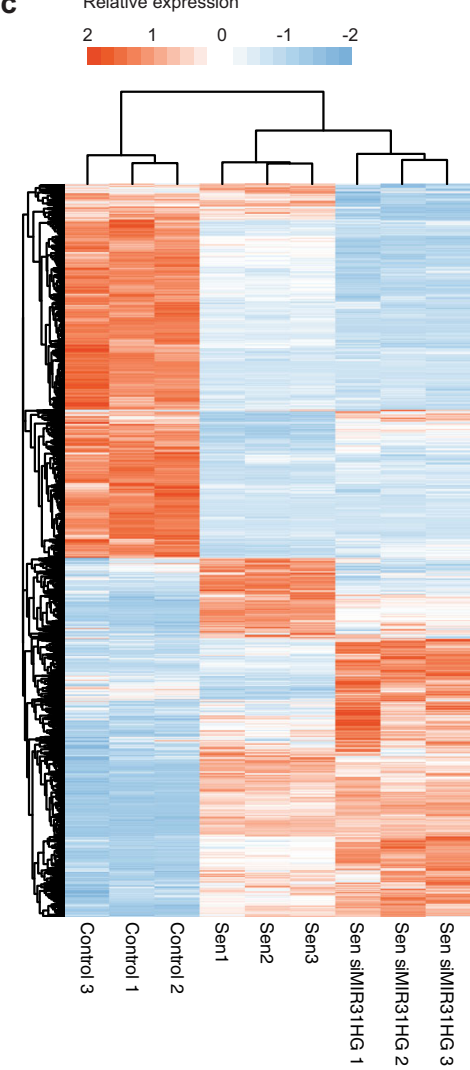

d e
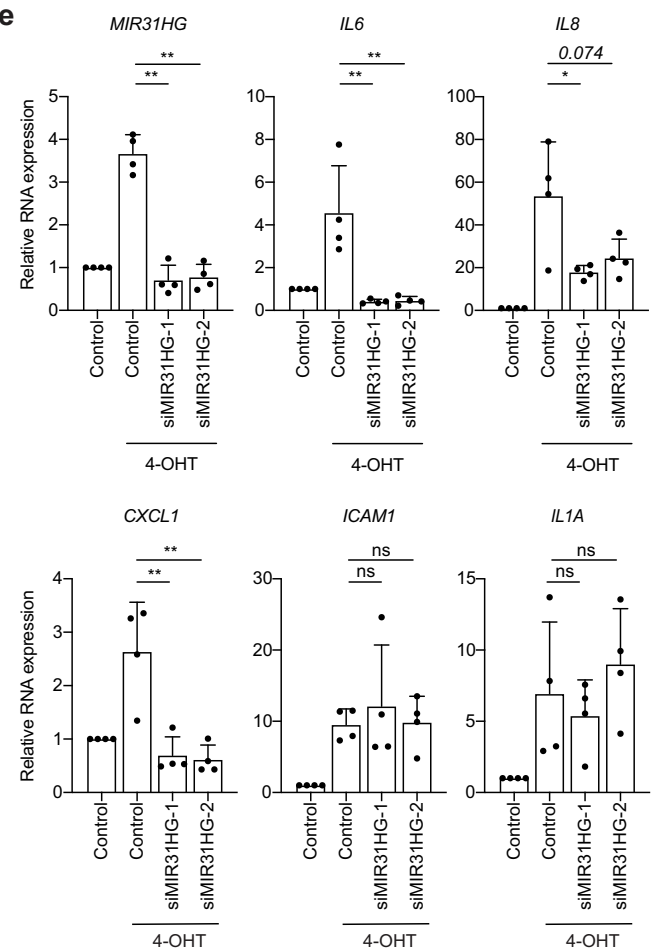

f

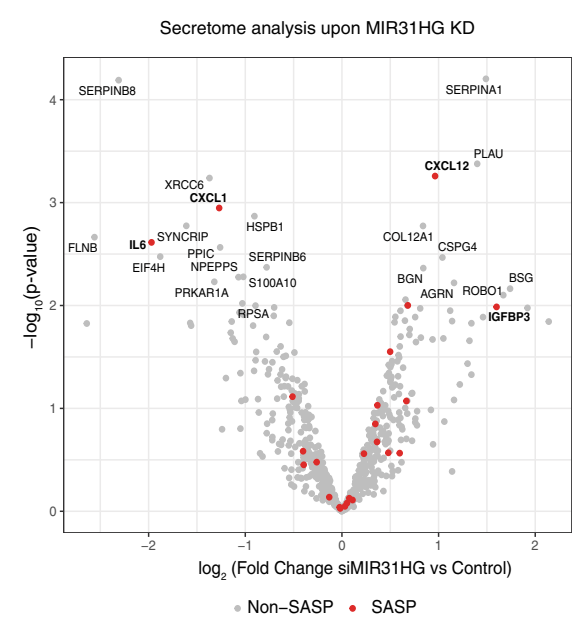

g
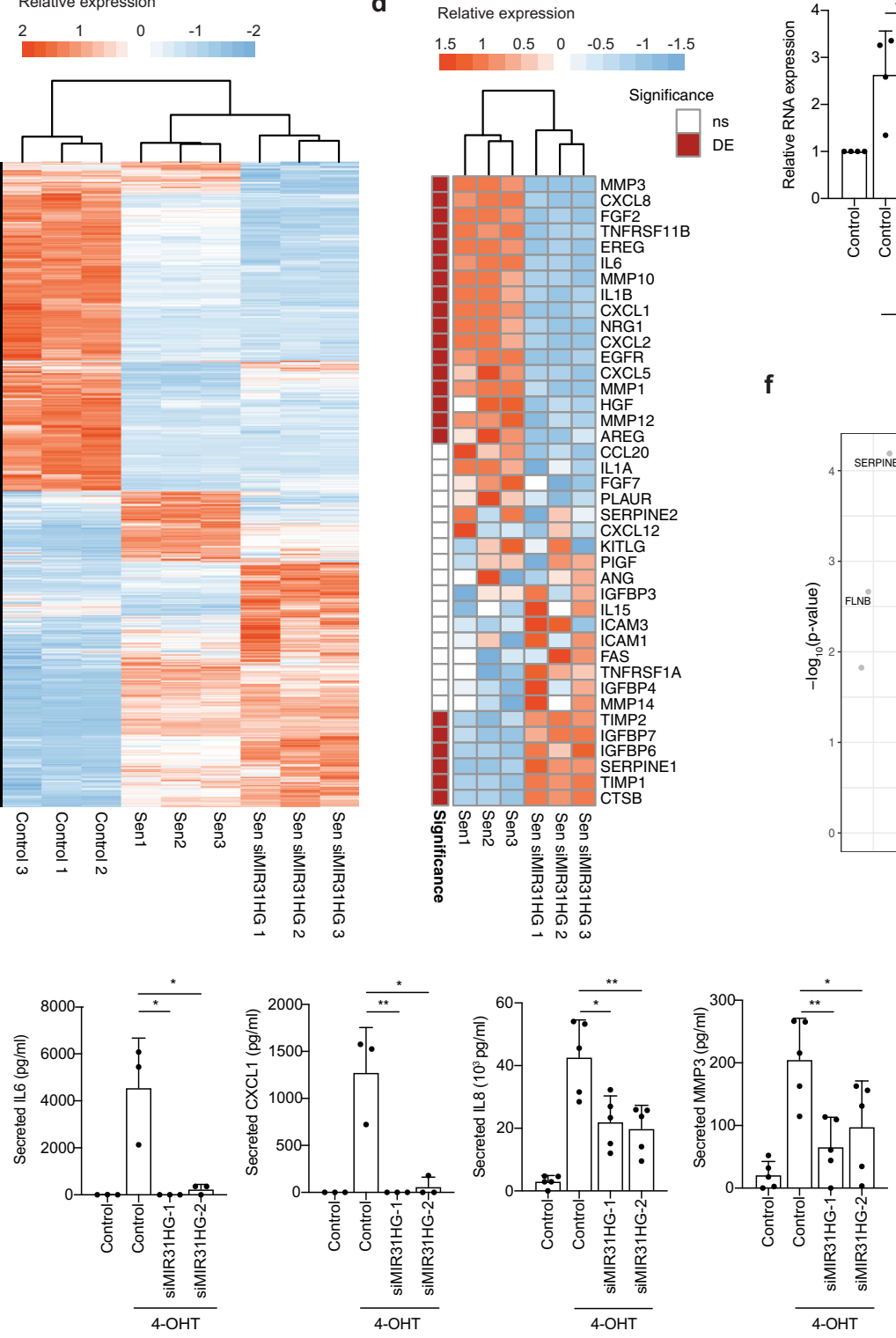

knock-down reduces the production of several SASP components during OIS already at the transcriptional level and these changes are reflected in the secretome.

Paracrine effect of the SASP of MIR31HG-depleted cells. To determine the paracrine effect of the SASP we induced senescence in cells transfected with control siRNA or siRNAs targeting
MIR31HG. After $72 \mathrm{~h} \mathrm{4-OHT} \mathrm{treatment} \mathrm{CM} \mathrm{was} \mathrm{harvested} \mathrm{and}$ used for subsequent analysis. The CM from proliferating cells without 4-OHT induction was also harvested at the same time point as control. To assess the potential of the SASP in inducing paracrine senescence, we incubated BJ and IMR90 WT cells with the different CM for $72 \mathrm{~h}$. Protein analysis of whole-cell extracts by western blot revealed that BJ and IMR90 cells growing in CM 
Fig. 1 MIR31HG knock-down decreases the induction of SASP components during BRAF-induced senescence. a Relative MIR31HG expression normalized to housekeeping genes (HPRT1 and RPLPO) in BJ ER:BRAF cells were treated with ethanol (Control) or $1 \mu \mathrm{M} 4-\mathrm{OHT}$ for $48 \mathrm{~h}(n=4)$. b Box plot showing MIR31HG expression in log2 (fpkm +1) units in thyroid carcinoma (THCA) and colorectal carcinoma (CRC) comparing BRAF mutant and BRAF wild-type tumours. The box plot represents the median (middle line), the box indicates the first and third quartiles and the whiskers indicate $\pm 1.5 \times$ interquartile range. Two-tailed Wilcoxon test was performed to compare the expression differences in the BRAF mutant and BRAF wild-type tumours (CRC BRAF_wt $=$ 309; CRC BRAF_mutant $=49$; THCA BRAF_mutant $=290$; THCA BRAF_wt $=199$ ). c Heat map showing relative expression of differentially expressed genes in BJ ER:BRAF cells (control or siMIR31HG), treated with ethanol (Control 1-3) or $1 \mu \mathrm{M} 4-\mathrm{OHT}$ for $48 \mathrm{~h}$ (Sen 1-3 and Sen siMIR31HG 1-3). d Heat map showing relative expression in RPKMs of a subset of SASP genes previously defined ${ }^{13}$ from the data provide in $\mathbf{a}$, where differentially expressed genes ('DE', FDR < 0.01) are indicated in red, unchanged (non-significant, ' $n s$ ') in white. e qRT-PCR analysis of selected components of the SASP normalized to housekeeping genes (HPRT1 and RPLPO) in BJ ER:BRAF cells transfected with the indicated siRNAs (Control or siMIR31HG1-2), treated with ethanol (Control) or $1 \mu \mathrm{M} 4-\mathrm{OHT}$ for $48 \mathrm{~h}$. The graphs show results compared to control ethanol-treated set to $1(n=4)$. $\mathbf{f}$ Mass spectrometry-based secretome analysis of senescent BJ ER:BRAF (1 $\mu \mathrm{M} 4-\mathrm{OHT})$ treated with siMIR31HG or control siRNA. The volcano plot shows differentially secreted proteins in MIR31HG knock-down senescent cells (Sen siMIR31HG) compared to control senescence cells (Sen) ( $-\log 10 p$ value along $y$-axis and log fold change along $x$-axis). Names are displayed for significantly changed proteins between secretomes ( $p v a l<0.01$ ) and SASP proteins are marked in red. $\mathbf{g}$ Secreted IL6, CXCL1, IL8 and MMP3 (pg/ml) measured by ELISA in the CM of BJ ER:BRAF (Control or siMIR31HG1-2) treated for $72 \mathrm{~h}$ with ethanol (Control) or $1 \mu \mathrm{M} 4$ $\mathrm{OHT}(n=3-5)$. All statistical significances were calculated using two-tailed Student's $t$-tests, except $\mathbf{b}$ where two-tailed Wilcoxon test was used. ${ }^{*} p<0.05$; ${ }^{\star \star} p<0.01 ;{ }^{\star \star \star} p<0.001$; ns non-significant. All error bars represent means \pm s.d. Source data are provided as a Source Data file.

a

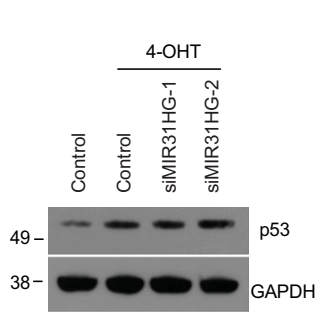

b

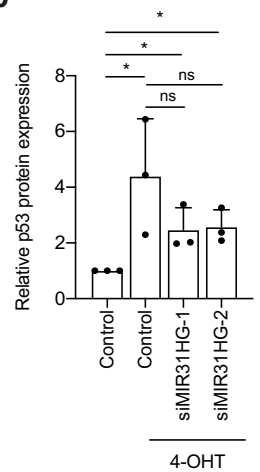

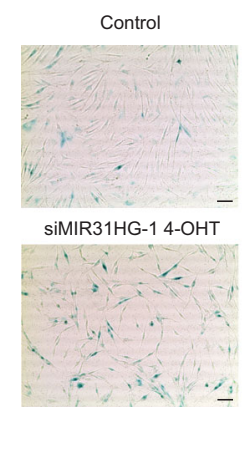

Control 4-OHT

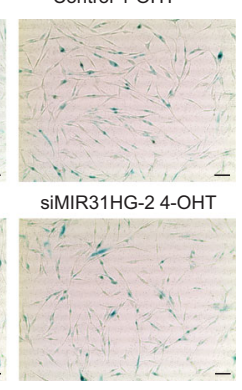

g

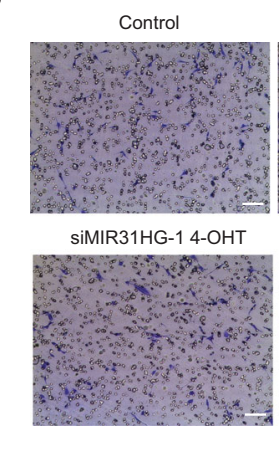

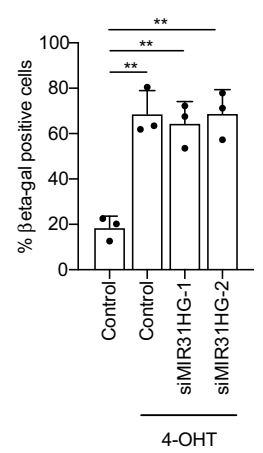

e

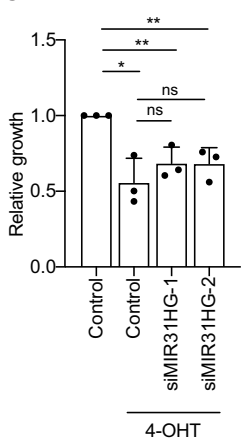

f

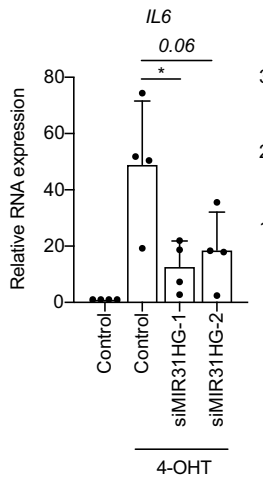

IL

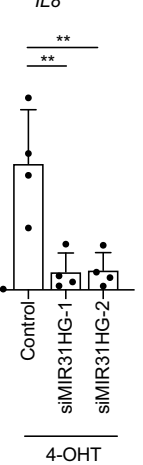

CXCL1

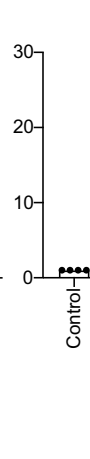

$\frac{\star \star}{* \star}$

\section{t}

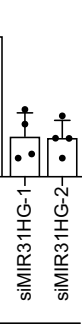

$4-\mathrm{OHT}$

Control 4-OHT

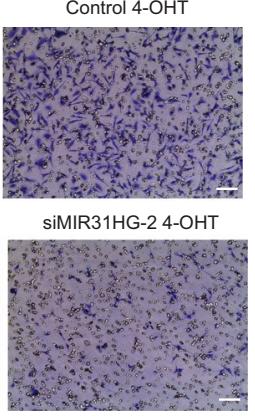

h

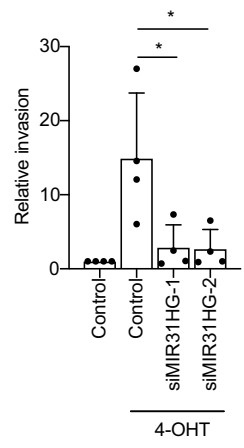

Fig. 2 The SASP of senescent MIR31HG knock-down cells induces senescence but not invasion in a non-autonomous manner. a Western blot analysis for p53 and GAPDH. in WT BJ cells incubated for $72 \mathrm{~h}$ with the CM collected from BJ ER:BRAF cells (Control or siMIR31HG1-2) treated with ethanol (Control) or $1 \mu \mathrm{M} 4-\mathrm{OHT}$ for $72 \mathrm{~h}$. Molecular weight marker is shown in $\mathrm{kDa}$. b Quantification of the western blot band intensities for p53 relative to GAPDH $(n=3)$. c Representative images of $\beta$-galactosidase staining from the same condition as indicated in a $(n=3)$. Scale bar: $50 \mu$ m. $\mathbf{d}$ Quantifiaction of the $\%$ of $\beta$-galactosidase-positive cells from $\mathbf{c}(n=3)$. e Relative growth by crystal violet staining dissolved in acetic acid and measured at $590 \mathrm{~nm}$ in WT BJ cells incubated for $72 \mathrm{~h}$ with the CM collected from BJ ER:BRAF cells (Control or siMIR31HG1-2) treated with ethanol (Control) or $1 \mu \mathrm{M} \mathrm{4-OHT} \mathrm{for} 72 \mathrm{~h}$. The graph shows the absorbance relative to the control cells set as $1(n=3)$. $\mathbf{f}$ qRT-PCR analysis of a subset of components of the SASP normalized to housekeeping genes (HPRT1 and RPLPO) in total RNA extracted from cells described in a. The graph shows the RNA expression relative to control ethanoltreated cells set to $1(n=4)$. $\mathbf{g}$ MDA-MB-231 invading cells through a matrigel membrane in contact with the CM collected from BJ ER:BRAF cells (Control or siMIR31HG) treated for $72 \mathrm{~h}$ with ethanol (Control) or $1 \mu \mathrm{M} 4-\mathrm{OHT}$. Representative images are shown in the figure $(n=4)$. Scale bar: $50 \mu \mathrm{m}$. h Quantification of the invading cells relative to control ethanol-treated cells $(n=3)$. All statistical significances were calculated using two-tailed Student $t$-tests, ${ }^{\star} p<0.05 ;{ }^{\star \star} p<0.01$, ns, non-significant. All error bars represent means \pm s.d. Source data are provided as a Source Data file.

from control senescent cells and MIR31HG knock-down senescent cells were able to mildly upregulate the senescence marker p53 (Fig. 2a, b and Supplementary Fig. 2a) as well as $\beta$ galactosidase (Fig. 2c, d) compared to proliferating cells. Consistently, a subset of p53 target genes ${ }^{31}$ was upregulated in BJ and
IMR90 cultured in CM from senescent cells in the presence and absence of MIR31HG (Supplementary Fig. 2b, c). Moreover, cells growing in $\mathrm{CM}$ from senescent cells showed decreased cell number after $72 \mathrm{~h}$, independently on $M I R 31 H G$ expression (Fig. 2e and Supplementary Fig. 2d). This was consistent with 
decreased expression of cell cycle-related genes (Supplementary Fig. 2e, f). However, the upregulation of inflammatory cytokines that occurs upon 4-OHT induction is reduced after MIR31HG depletion (Fig. 2f). Acosta et al. ${ }^{12}$ reported that the transforming growth factor- $\beta$ (TGF- $\beta$ ) signalling pathway is responsible for the paracrine senescence effect. As expected, RNA levels of TGF $\beta$ target genes were upregulated in BJ ER:BRAF upon 4-OHT treatment compared to control proliferating cells (Supplementary Fig. 2g), while MIR31HG knock-down did not affect this increase. Moreover, the protein level of pSMAD2, downstream effector of TGF $\beta$ signalling, was upregulated during OIS in control as well as in MIR31HG knock-down senescent cells (Supplementary Fig. 2h). Similarly, WT BJ cells discretely activated TGF $\beta$ signalling when incubated with $\mathrm{CM}$ from control senescent cells and also with CM from MIR31HG knock-down senescent cells (Supplementary Fig. 2i, j). These results demonstrate that the TGF $\beta$ signalling pathway remains active in MIR31HG knockdown senescent cells suggesting that its activation could be responsible for the paracrine senescence induction. To determine the role of the SASP in promoting cancer cell invasion, we performed transwell invasion assays using the different CM described above as chemoattractant in the lower chamber of the transwell for MDA-MB-231 breast cancer cells. After $48 \mathrm{~h}$ incubation a higher number of MDA-MB-231 cells exposed to CM from senescent cells invaded through the matrigel membrane compared to proliferating CM (Fig. $2 \mathrm{~g}$, h). In contrast, the CM of MIR31HG knock-down senescent cells did not promote invasion (Fig. $2 \mathrm{~g}, \mathrm{~h}$ ). These results demonstrate that the paracrine senescence effect is retained in the SASP of MIR31HG knock-down senescent cells but not the induction of paracrine invasion. These findings suggest that the effect of MIR31HG in the SASP production does not occur at a general level but that only a subset of components is inhibited.

MIR31HG depletion reduces CEBPB and NF- $\mathrm{kB}$ activation in OIS. As NF- $\mathrm{KB}$ and CEBPB regulate the expression of many SASP genes by stimulating their transcription ${ }^{11,32,33}$, we investigated the possibility that MIR31HG knock-down affected the abundance or the activation of these transcription factors. As expected, the protein levels of CEBPB and activated phosphorylated RELA (p-RELA) (component of the NF- $\kappa B$ complex) increased during BRAF activation (Fig. 3a, b). Interestingly, MIR31HG knock-down in senescent cells reduced CEBPB protein expression and activated p-RELA (Fig. 3a, b) without affecting their mRNA levels (Supplementary Fig. 3a). In accordance, binding of CEBPB to the IL6 promoter, a canonical CEBPB target, decreased significantly upon MIR31HG knock-down compare to control senescent conditions (Fig. 3c). Consistently, NFKB translocation to the nucleus was inhibited upon MIR31HG depletion (Fig. 3d and Supplementary Fig. 3b). Moreover, the signalling pathway upstream NF- $\mathrm{kB}$ activation was affected in MIR31HG knock-down senescent (Supplementary Fig. 3c). These results suggest that MIR31HG acts upstream of both CEBPB and NF- $\kappa B$ transcriptional activation.

MIR31HG depletion decreases IL1A translation in OIS. IL1A has been reported to function as an upstream regulator of the $\mathrm{SASP}^{34}$. In line with this, addition of human recombinant IL1A (hr-IL1A) in our model system induced expression of SASP components at the RNA level (Supplementary Fig. 3d). Blocking IL1A signalling using siRNA against IL1A reduced the levels of CEBPB expression upon senescence as well as the RNA levels of different components of the SASP (Supplementary Fig. 3e, f). To validate the paracrine role of IL1A in the SASP induction, we knocked down IL1A in senescent cells and use this CM to assess the expression of SASP components by qRT-PCR in recipient BJ and IMR90 cells. The CM from IL1A knock-down senescent cells was not able to induce paracrine expression of SASP components in both cells lines BJ and IMR90 (Supplementary Fig. 3g). Interestingly, while IL1A mRNA was not affected by the levels of MIR31HG (Fig. 1e), IL1A protein levels were strongly reduced in MIR31HG knock-down senescent cells compared to control senescent cells as measured by western blot of the total lysate (Fig. 3e, f) and by immunofluorescence staining (Fig. 3g). ICAM1, which was not affected by MIR31HG depletion at the RNA level (Fig. 1e), did not show any protein decreased, suggesting some degree of specificity (Supplementary Fig. 3h, i).

Addition of human recombinant IL1A (hr-IL1A) rescued the incapacity of MIR31HG knock-down senescent cells to induce SASP RNA transcription (Fig. 3h), IL6 secretion (Fig. 3i), and NF-kB nuclear translocation (Supplementary Fig. 3j).

To test whether MIR31HG would be regulating IL1A at a translational level, we performed polysome profiling in control senescent cells and senescent cells upon depletion of MIR31HG. The profiles obtained upon sucrose gradient separation in both conditions showed no major changes in polysome distribution, indicating no changes in global protein synthesis (Fig. 3j). Analysing the distribution of IL1A mRNA through the gradient we observed the majority of the transcript present in the heavy polysome fractions, indicative of high level of translation (Fig. 3k). Remarkably, a significant decrease of IL1A mRNA in these fractions was observed in MIR31HG knock-down senescent cells compared to control senescent cells (Fig. 31 and Supplementary Fig. 3k). Distribution of $A C T B$ mRNA through the gradient did not show any difference (Fig. 31 and Supplementary Fig. 3k). Despite the decrease in mRNA levels of other cytokines such as IL6, the similar distribution of their mRNAs through the gradient indicates an equal translation efficiency suggesting that the effect of MIR31HG on translation is specific for IL1A (Fig. 31 and Supplementary Fig. 3k). To validate that reduced IL1A protein levels was due to an effect of MIR31HG on translation and not other related processes such as protein stability, we performed AHA pulse labelling and coupling of newly synthesized proteins to biotin followed by streptavidin pull-down and immunoblotting. We confirmed that MIR31HG-depleted senescent cells contained less newly synthesized IL1A compared to control senescent cells, whereas the amount of GAPDH or Vinculin remained unaltered (Fig. $3 \mathrm{~m}$ ). MTOR signalling has been recently involved in SASP regulation through IL1A signalling ${ }^{35}$. However, MIR31HG knockdown did not affect mTOR signalling activation (Supplementary Fig. 31), indicating an alternative mechanism for MIR31HG regulation of IL1A. These findings suggest that MIR31HG is implicated in the modulation of the SASP by regulating IL1A translation independent of the mTOR signalling pathway.

MIR31HG interacts with YBX1. In order to elucidate the mechanism by which $M I R 31 H G$ exerts its function in regulating the SASP, we purified endogenous MIR31HG with its associated proteins from UV-crosslinked senescent BJ ER:BRAF cells using antisense oligonucleotides containing locked nucleic acid (ASOs) complementary to the MIR31HG sequence coupled to magnetic beads (Fig. 4a). Oligonucleotides against the RNA sequence of luciferase, not expressed in BJ ER:BRAF cells, were used as control. Mass spectrometry analysis of MIR31HG-associated proteins revealed a low number of significantly enriched proteins among which several RNA-binding proteins (Fig. $4 \mathrm{~b}$ and Supplementary Data 2). MIR31HG has been previously shown to interact with $\mathrm{I} \kappa \mathrm{B} \alpha$ during osteogenic differentiation regulating NF- $\mathrm{kB}$ activation ${ }^{26}$. However, we did not detect IאBa in our pulldown experiments. The majority were heterogeneous nuclear 
a

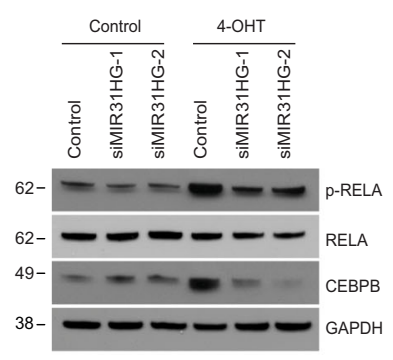

b

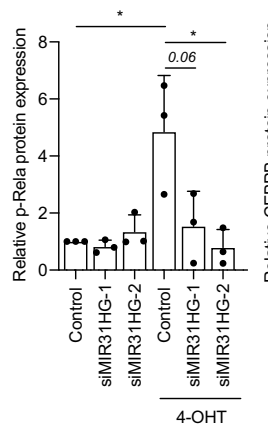

C

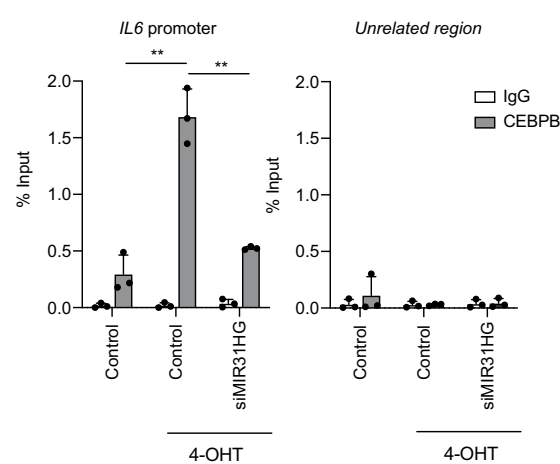

$\lg G$

CEBPB

d
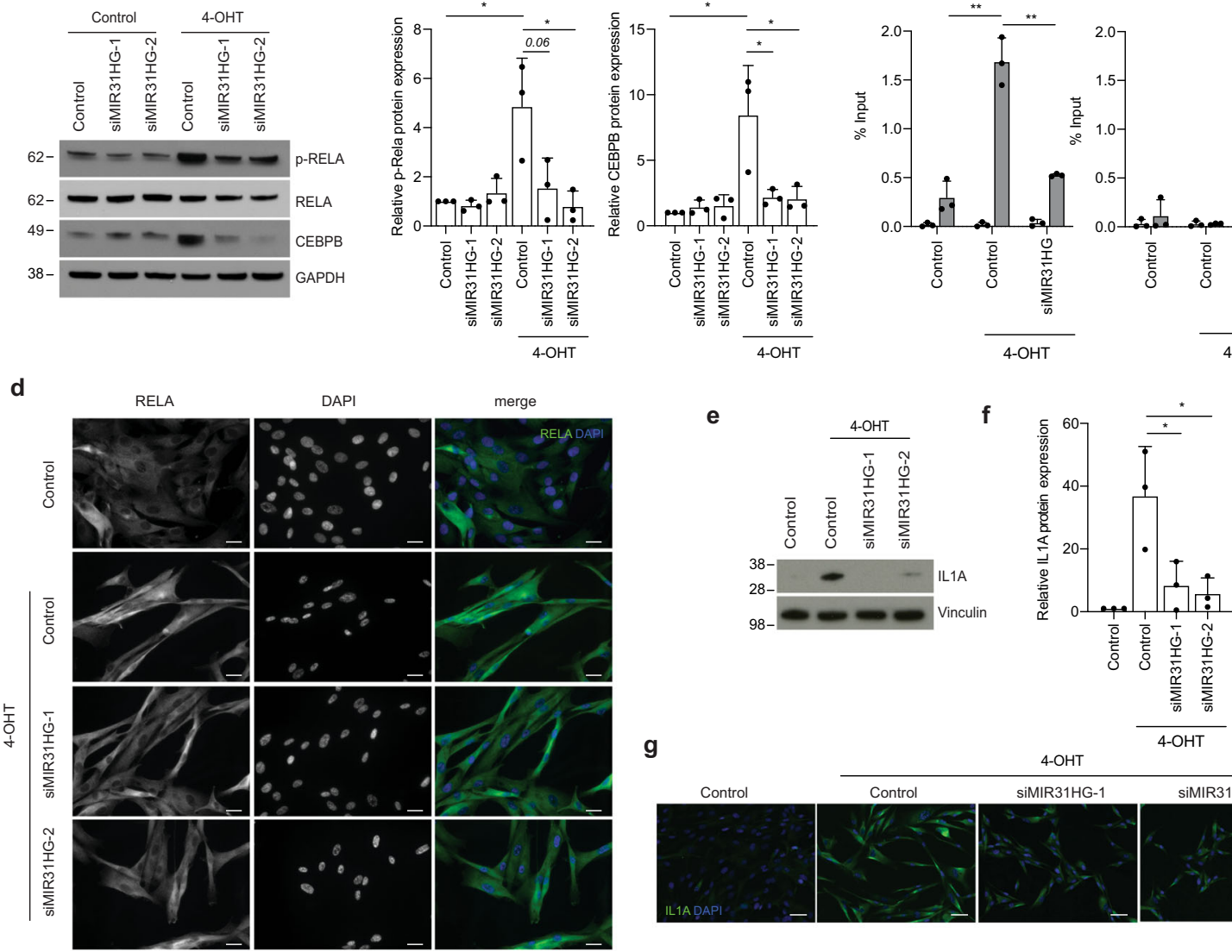

g

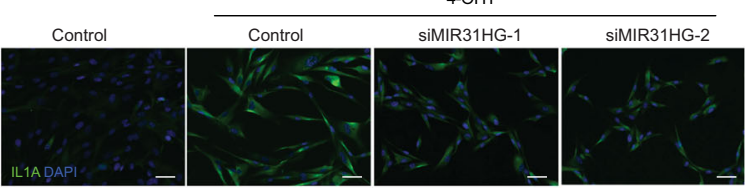

h
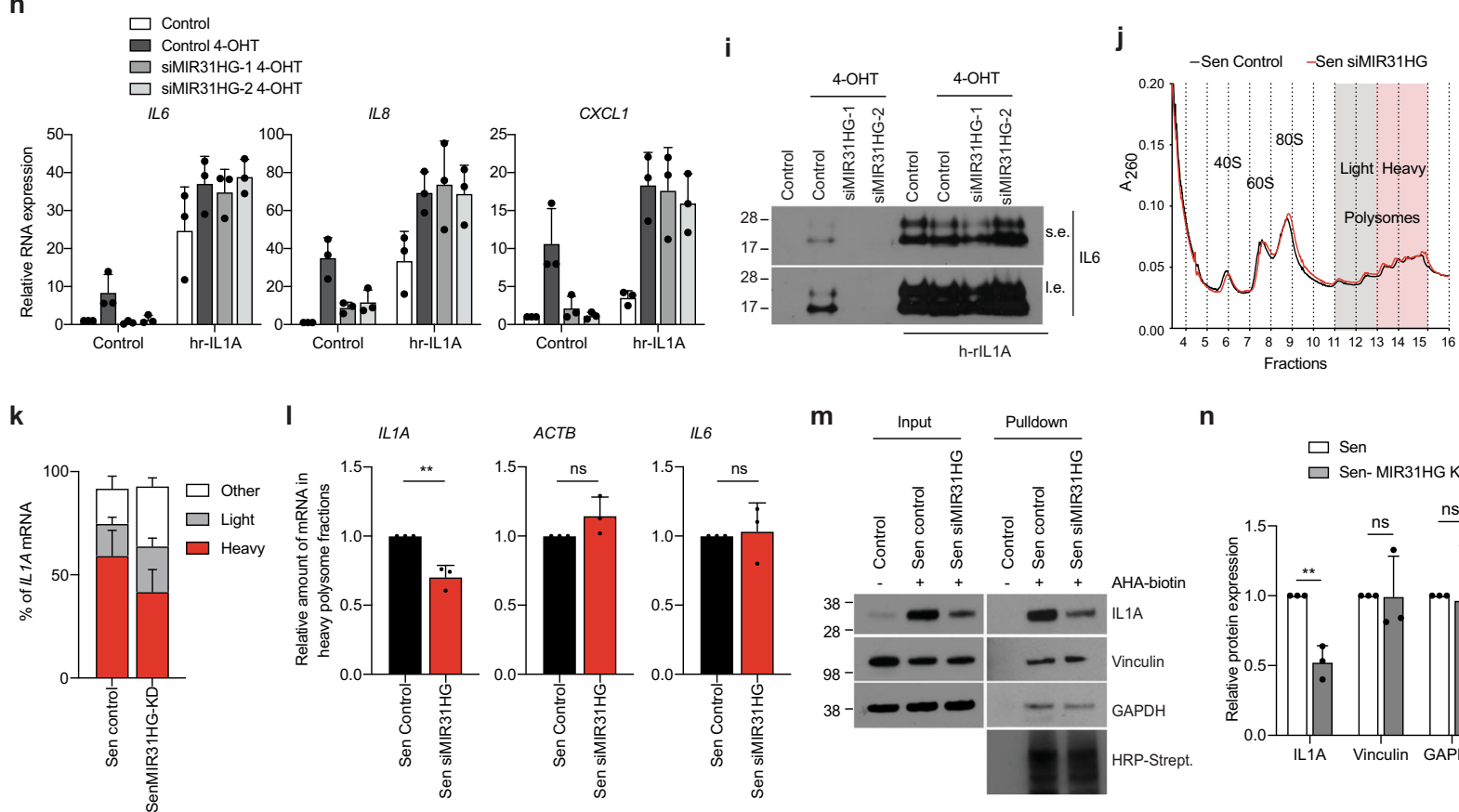

m

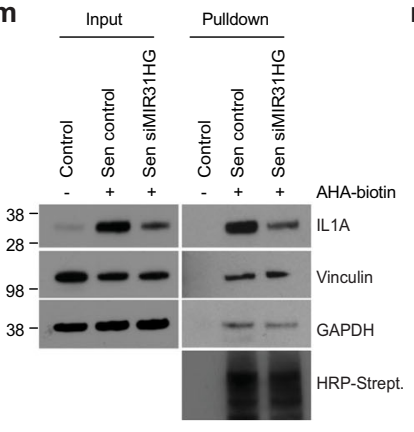

n

$\square$ Sen

$\square$ Sen-MIR31HG KD

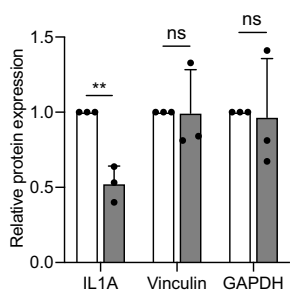

ribonucleoproteins or other predominantly nuclear proteins involved in RNA processing. Recent reports have demonstrated the role of PTBP1 in regulating the SASP composition through the regulation of the alternative splicing of genes implicated in intracellular trafficking ${ }^{36}$. However, since MIR31HG localizes mainly in the cytoplasm during OIS (Supplementary Fig 4a) we focused on YBX1 as a protein with defined cytoplasmic functions (Fig. 4b).
YBX1 knock-down phenocopies MIR31HG depletion. YBX1 has been implicated in several cytoplasmic processes, such as translation or mRNA stability among others ${ }^{37}$. According to previous findings, YBX1 prevents senescence in epidermal progenitors and knock-down of YBX1 induces senescence features in keratinocytes $^{38}$. Depletion of YBX1 in untreated proliferating BJ ER:BRAF resulted in decreased proliferation and p21 increase, 
Fig. 3 MIR31HG knock-down decreases IL1A translation. a Western blot for p-RELA, RELA, CEBPB and GAPDH of BJ ER:BRAF cells (Control or siMIR31HG1-2) treated with ethanol (Control) or $1 \mu \mathrm{M} \mathrm{4-OHT}$ for $72 \mathrm{~h}$. Molecular weight marker is shown in kDa. $\mathbf{b}$ Quantification of the p-RELA and CEBPB western blot band intensities relative to GAPDH $(n=3)$. c Chromatin immunoprecipitation followed by qPCR for CEBPB binding to the IL6 promoter and to an unrelated region in BJ ER:BRAF cells (Control or siMIR31HG1) treated with ethanol (Control) or $1 \mu \mathrm{M} 4-\mathrm{OHT}$ for $48 \mathrm{~h}$. The graph shows the percentage of the input that binds CEBPB $(n=3)$. $\mathbf{d}$ Immunofluorescence analysis for RELA and DAPI of BJ ER:BRAF cells (Control or siMIR31HG1-2) treated with ethanol (Control) or $1 \mu \mathrm{M} 4-\mathrm{OHT}$ for $72 \mathrm{~h}$. Representative images are shown in the figure $(n=3)$. Scale bar: $20 \mu \mathrm{m}$. e Western blot for IL1A in BJ ER:BRAF cells (Control or siMIR31HG1-2) were treated with ethanol (Control) or $1 \mu \mathrm{M} \mathrm{4-OHT} \mathrm{for} 72 \mathrm{~h}$. Molecular weight marker is shown in kDa $(n=3)$. $\mathbf{f}$ Quantification of IL1A western blot band intensities relative to Vinculin $(n=3)$. $\mathbf{g}$ Immunofluorescence of IL1A and DAPI in BJ ER:BRAF cells (Control or siMIR31HG1-2) treated with ethanol (Control) or $1 \mu \mathrm{M} 4-\mathrm{OHT}$ for $72 \mathrm{~h}$. Representative merged images are shown in the figure $(n=3)$. Scale bar: $50 \mu \mathrm{m}$. $\mathbf{h}$ Relative RNA expression for the indicated SASP factors in BJ ER:BRAF cells transfected with the indicated siRNAs (Control or siMIR31HG1-2), treated with ethanol (Control) or $1 \mu \mathrm{M} \mathrm{4-OHT} \mathrm{for} 48 \mathrm{~h}$, in the absence or presence of $10 \mathrm{ng} / \mathrm{ml}$ of h-rIL1A for $2 \mathrm{~h}$ before RNA extraction $(n=3)$. i Western blot for IL6 from precipitated protein from the media in the conditions indicated in $\mathbf{h}$ in the absence or presence of $10 \mathrm{ng} / \mathrm{ml}$ of $\mathrm{h}$-rlL1A for $24 \mathrm{~h}$ before harvesting the $\mathrm{CM}(n=3)$. S.e. short exposure, l.e. long exposure. $\mathbf{j}$ Polysome profile performed by sucrose gradient separation in senescent BJ ER:BRAF control cells (Sen Control, black) or siMIR31HG cells (Sen siMIR31HG, red) treated with $1 \mu \mathrm{M} 4-\mathrm{OHT}$ for $72 \mathrm{~h}$. $Y$-axis shows the absorbance at $260 \mathrm{nM}$ and $\mathrm{X}$-axis shows the number of the fractions collected. Red area shows the heavy polysome fractions and grey area shows the light polysome fractions. One representative experiment is shown in the figure $(n=3)$. $\mathbf{k}$ Distribution of the amount of ILTA mRNA in the heavy polysome (red) light polysome (grey) or other fractions (white) from the experiment in $\mathbf{g}$. I Relative amount of ILTA, IL6 and ACTB mRNA present in the heavy polysome fractions in the experiment described in $\mathbf{j}$. m Western blot analysis of newly synthesized IL1A, Vinculin and GAPDH levels in control senescent cells and MIR31HG- depleted senescent cells purified by AHA pulse-labelling and coupling to biotin followed by streptavidin pull-down. As control, proliferating cells without AHA labelling is shown. HRPstreptavidin shows the uniform labelling of newly synthesized proteins coupled to biotin. A representative experiment is shown ( $n=3$ ). $\mathbf{n}$ Quantification of IL1A, Vinculin and GAPDH western blot band intensities from pulldown samples in senescence (Sen, white) and senescence MIR31HG KD cells (SenMIR31HG KD, grey) $(n=3)$. All statistical significances were calculated using two-tailed Student's $t$-tests, ${ }^{\star} p<0.05 ;{ }^{* \star} p<0.01$; ns non-significant. All error bars represent means \pm s.d. Source data are provided as a Source Data file.

although p53 levels were strongly downregulated (Supplementary Fig. 4b, c). Interestingly, knock-down of YBX1 in BRAF-induced senescent cells mimicked MIR31HG knock-down phenotype. SASP components were decreased at RNA level in YBX1 knockdown senescent cells compared to control senescent cells (Fig. 4c, d and Supplementary Data 3). Likewise, reduction in the secretion of IL6 and CXCL1 upon YBX1 knock-down were comparable to the levels following MIR31HG knock-down (Figs. 1e and 4e). Furthermore, IL1A protein levels were strongly reduced (Fig. 4f, g) whereas the mRNA level remained unaltered (Fig. 4d).

Formaldehyde crosslinked RNA immunoprecipitation (CLIP) of GFP-tagged YBX1 validated its interaction with MIR31HG (Fig. 4h). As a positive control, we found YBX1 binding its own RNA as previously reported ${ }^{39}$. Interestingly, YBX1 binds IL1A mRNA whereas other cytokine mRNAs are bound to a lesser extent (Fig. 4h). Furthermore, no binding to abundant nuclear RNAs (MALAT1) or the mitochondrial RNAs previously used as negative controls ${ }^{40}$ was identified. To identify the YBX1-binding sites in MIR31HG we performed in silico prediction based on previous iCLIP studies ${ }^{41,42}$, and identified five putative binding sites (Fig. 4i). We generated MIR31HG mutants harbouring deletions including the predicted binding sites (Fig. 4i) to perform electrophoretic mobility shift assays (EMSA), incubating the corresponding in vitro-transcribed RNA with recombinant YBX1. $N D 4$, a mitochondrial transcript previously used as a negative control (Fig. 4h), did not produce a shift indicating the absence of binding, whereas the full-length $M I R 31 H G$ (WT) resulted in a band shift when incubated with increasing amounts of YBX1 (Fig. 4j). Mutant 1 and 5 (Mut1 and Mut5) were able to bind YBX1 to the same extent as the WT, whereas mutants 2, 3 and 4 (Mut2, Mut3 and Mut4) were not (Fig. 4j). To validate these results, we performed competition assays incubating ${ }^{32} \mathrm{P}$-labelled MIR31HG WT transcript with increasing amounts of unlabelled Mut5 or Mut3. We observed that only mut 5 competed for the binding of YBX1 (Fig. 4k). These results indicate that the predicted binding site BS3 in MIR31HG is required for YBX1 binding.

To study the biological function of the MIR31HG and YBX1 interaction, we analysed the stability and localization of MIR31HG upon YBX1 knock-down, since stabilization of RNAs is a well-described function of cytoplasmic YBX1 (refs. ${ }^{43,44}$ ). We did not observe changes in MIR31HG expression nor localization upon YBX1 knock-down (Supplementary Fig. 4d, e). Moreover, protein levels of YBX1 did not change upon depletion of MIR31HG (Supplementary Fig 4f).

YBX1 is phosphorylated at serine 102 by RSK in OIS. Several modifications which can affect YBX1 function have been reported ${ }^{45}$. Phosphorylation of serine in position 102 has been shown to be involved in the regulation of translation ${ }^{46}$. We therefore studied the phosphorylation status of YBX1 and the putative implication of MIR31HG in YBX1 regulation. In order to analyse p-YBX1 in BRAF-induced senescence, we used an antibody that recognizes $\mathrm{p}$-YBX1 at position $\mathrm{S} 102$ (p-YBX1 ${ }^{\mathrm{S} 102}$ ). Interestingly, we detected increased levels of this modification at different time points after BRAF induction (Fig. 5a and Supplementary Fig. 5a). Different kinases have been reported to be responsible for S102 YBX1 phosphorylation such as AKT and RSK $^{47,48}$. We analysed the levels of activated AKT at different time points after 4-OHT induction and we observed that pAKT decreased over time to nearly undetected levels already after $24 \mathrm{~h}$ treatment (Supplementary Fig. 5b). The kinase RSK, however, is activated at early points during senescence induction and remain active at later time points (Fig. 5a and Supplementary Fig. 5a) suggesting that YBX1 might be a substrate for RSK during OIS. To investigate the role of RSK in YBX1 phosphorylation in BRAF-OIS, we treated the cells with specific RSK inhibitors. Treatment of senescent cells with the inhibitor FMK reduced the levels of $\mathrm{p}-\mathrm{YBX1}^{\mathrm{S} 102}$ (Fig. 5b and Supplementary Fig. 5c). Moreover, BI-D780, a more specific RSK inhibitor, was able to completely abolish phosphorylation of YBX1 in senescent cells (Fig. 5b and Supplementary Fig. 5c). Furthermore, overexpression of RSK resulted in an increased level of $\mathrm{p}-\mathrm{YBX1}^{\mathrm{S} 102}$ (Supplementary Fig. 5d). Our results conclude that YBX1 is phosphorylated by RSK kinase in a BRAF-dependent manner.

pYBX1 $^{\mathrm{S} 102}$ induces translation of IL1A. It has been previously shown that YBX1 can promote translation of specific transcripts ${ }^{49,50}$. We next wondered whether $\mathrm{p}$-YBX1 ${ }^{\mathrm{S} 102}$ could impact IL1A translation. As expected, BRAF-induced senescence 
a

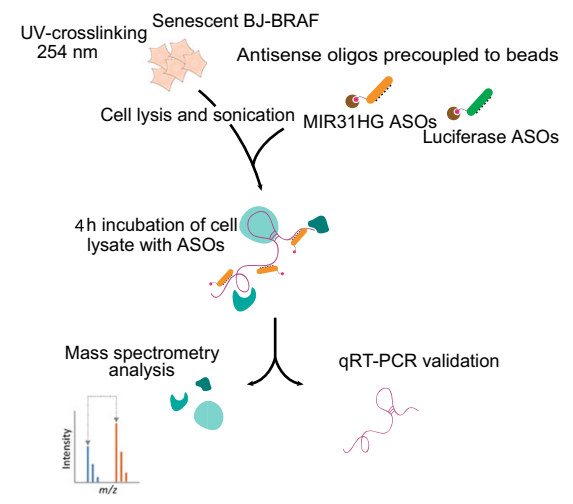

d

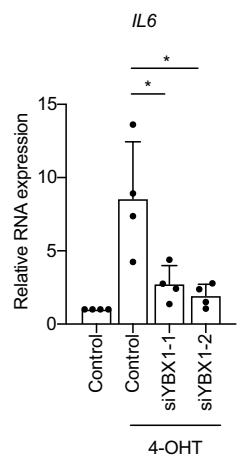

e

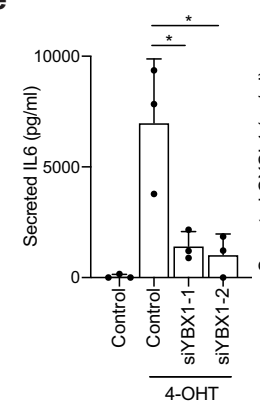

i
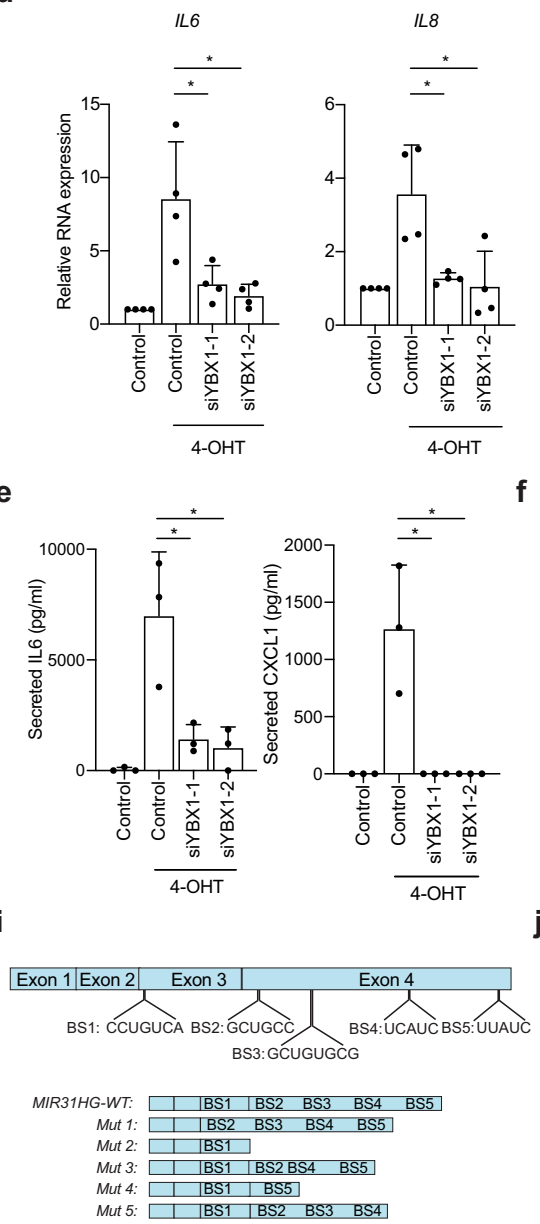

j b

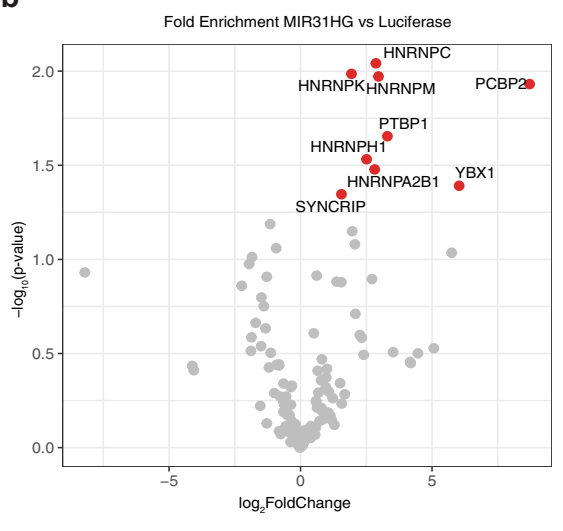

Significant $\bullet$ Not Sig $\bullet$ pval $<0.05$
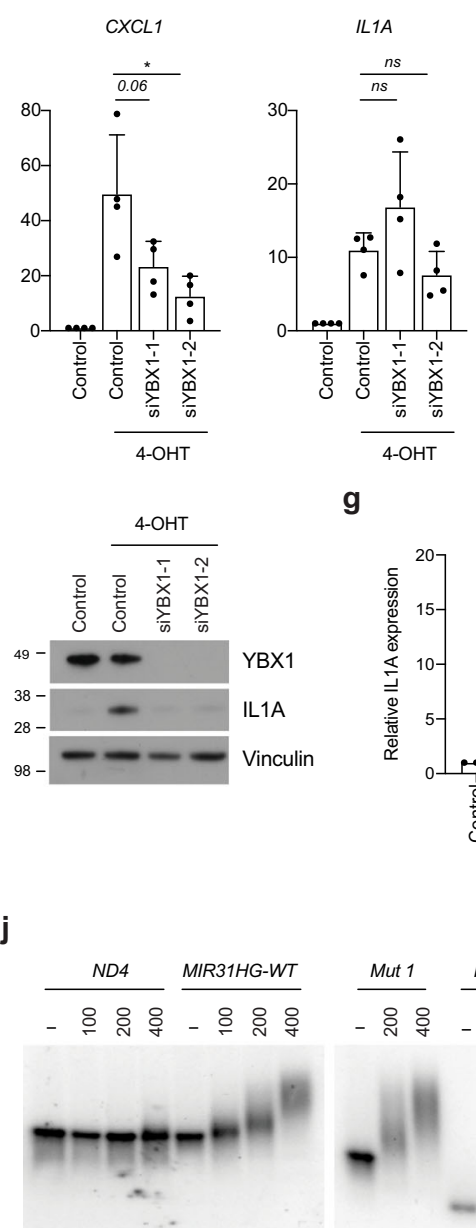

g

C
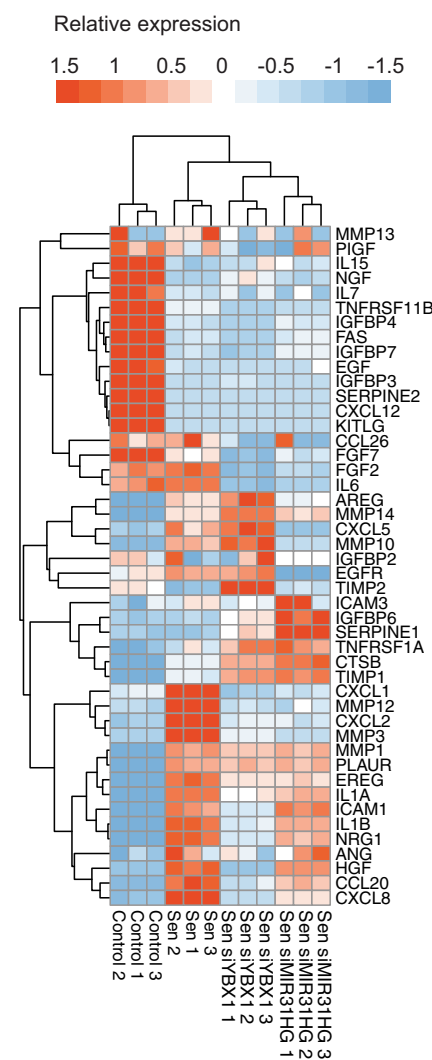

h

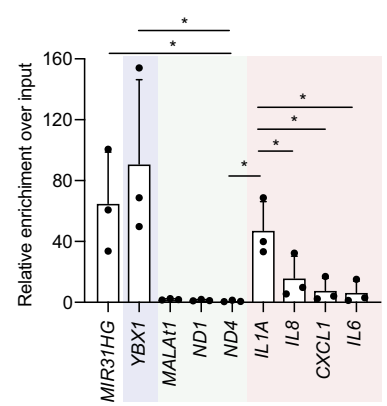

k

k YBX1 (400ng)

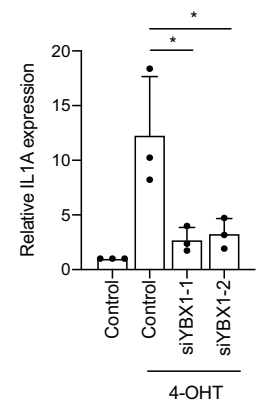

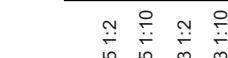

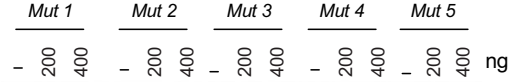
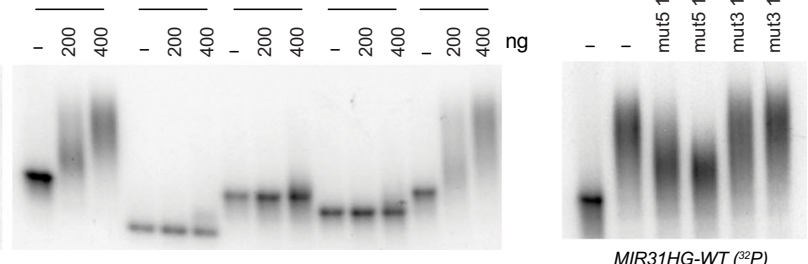

resulted in an upregulation of IL1A protein levels compared to control untreated cells (Fig. 5c and Supplementary Fig. 5e). Interestingly, treatment with the RSK inhibitor BI-D1780 failed to upregulate IL1A during senescence (Fig. 5c and Supplementary Fig. 5e). YBX1 has been recently implicated in cytokine translation by binding the $3^{\prime} \mathrm{UTR}$ of their $\mathrm{mRNAs} \mathrm{s}^{38}$. Using reporter plasmids harbouring the $3^{\prime}$ UTR of IL1A after luciferase gene we demonstrated that a WT version of YBX1 is able to increase luciferase translation in response to 4 -OHT induction (Fig. 5d). A mutant that is not able to be phosphorylated at S102 (S102A) failed to induce translation whereas a phosphomimic mutant (S102D) increased translation even in the absence of 4-OHT (Fig. 5d and Supplementary Fig. 5f). These results suggest that p-
YBX1 binds $I L 1 A 3^{\prime} \mathrm{UTR}$ to increase its translation. We assessed the binding capacity of the different phosphorylated versions of YBX1 to IL1A mRNA and to MIR31HG by RIP. All the proteins showed a similar binding to their targets suggesting that phosphorylation at $\mathrm{S} 102$ is not affecting YBX1 binding capacity (Fig. 5e and Supplementary Fig. 5g). We next characterized the role of the $\mathrm{p}-\mathrm{YBX} 1^{\mathrm{S} 102}$ in invasion using transwell assays. The $\mathrm{CM}$ from ethanol treated (control) or $1 \mu \mathrm{M}$ 4-OHT BJ ER:BRAF cells transfected with control siRNAs or siRNAs against RSK, YBX1 or MIR31HG were used as chemoattractant in the lower chamber of the transwell for MDA-MB-231 breast cancer cell invasion. After $24 \mathrm{~h}$ a higher number of MDA-MB-231 cells exposed to CM from senescent cells invaded through the matrigel 
Fig. 4 MIR31HG interacts with YBX1 and YBX1 knock-down phenocopies MIR31HG depletion. a Schematic representation of the pulldown procedure. b Cellular extracts from BJ ER:BRAF (Control or siMIR31HG) treated with $1 \mu \mathrm{M} 4-\mathrm{OHT}$ for $72 \mathrm{~h}$ were incubated with antisense oligos, enriched proteins extracted and subjected to LC-MS analysis (see 'Methods'). The volcano plot highlights proteins enriched in the MIR31HG pulldown analysis compared to a luciferase control pull down. Marked in red are protein with $p$ value $<0.05$. c Heat map showing the relative expression of significant differentially expressed SASP genes in BJ ER:BRAF cells (control or siMIR31HG) treated with ethanol (Control 1-3) or 1 $\mu$ M 4-OHT for 48 h (Sen 1-3, Sen siMIR31HG 1-3, Sen YBX1-KD1-3). d Relative RNA expression of selected components of the SASP normalized to housekeeping genes (HPRT1 and RPLPO) in BJ ER:BRAF cells transfected with the indicated siRNAs (Control or siYBX1, 1-2), treated with ethanol (Control) or $1 \mu \mathrm{M} 4-\mathrm{OHT}$ for $48 \mathrm{~h}$. The graph shows results compared to control ethanol-treated set to $1(n=4)$. e Secreted IL6 and CXCL1 ( $\mathrm{pg} / \mathrm{ml}$ ) measured by ELISA in the CM of BJ ER:BRAF (Control or siYBX1, $1-2)$ treated for $72 \mathrm{~h}$ with ethanol (Control) or $1 \mu \mathrm{M} 4-\mathrm{OHT}(n=3)$. $\mathbf{f}$ Western blot for IL1A in BJ ER:BRAF cells (Control or siYBX1, 1-2) were treated with ethanol (Control) or $1 \mu \mathrm{M} 4-\mathrm{OHT}$ for $72 \mathrm{~h}$. Molecular weight marker is shown in $\mathrm{kDa}(n=3)$. $\mathbf{g}$ Quantification of the IL1A western blot band intensities relative to Vinculin $(n=3)$. h Relative RNA binding using GFP-YBX1 in 4-OHT-treated BJ ER:BRAF, represented as the percentage of the input bound relative to an empty GFP cell line. YBX1 was used as a positive control (blue), MALAT1, ND1, and ND4 binding as negative controls (green) and cytokines binding (pink). The results are shown as the percentage of input relative to an empty GFP cell line treated in the same conditions $(n=3)$. $\mathbf{i}$ Top, schematic representation of MIR31HG with the putative YBX1-binding sites (BS) found in published iCLIP data. BS1-3 were found in Goodarzi et al. iCLIP data and BS54 were retrieved from Wu et al. dataset. Bottom, representation of MIR31HG truncations (Mut1 to Mut5). $\mathbf{j}$ EMSA showing the in vitro binding of $2 \mathrm{nM}$ of the corresponding radiolabelled transcript and the indicated amounts of recombinant YBX1. BSA at the highest concentration (400 ng) was used as a negative control $(n=3)$. $\mathbf{k}$ EMSA showing the in vitro binding of $400 \mathrm{ng}$ of $\mathrm{YBX} 1$ to $2 \mathrm{nM}$ of the radiolabelled MIR31HG wild type in competition with the indicated amounts of unlabelled Mut5 or Mut3 $(n=3)$. All statistical significances were calculated using two-tailed Student's $t$-tests, ${ }^{\star} p<0.05$; ns non-significant. All error bars represent means \pm s.d. Source data are provided as a Source Data file.

membrane compared to control CM (Supplementary Fig. 5h, i). In contrast, the CM of RSK and YBX1 knock-down senescent cells promoted limited invasion as well as the CM of MIR31HGdepleted cells (Supplementary Fig. 5h, i). These results show that RSK and YBX1 are required for invasion. In order to further analyse the role of YBX1 phosphorylation, we performed transwell assays using BJ ER:BRAF cells expressing the different YBX1 constructs described above. Overexpression of all forms of YBX1 increased invasion independently of its phosphorylation status (Fig. 5f, g). However, under senescence conditions, overexpression of WT YBX1 promoted invasion to a similar extent as that of the S102D phosphor-mimic mutant, whereas the invasion was reduced when overexpressing the S102A mutant (Fig. 5f, g). Although endogenous YBX1 was depleted using siRNAs targeting the $3^{\prime}$ UTR, residual YBX1 might explain the fact that all the constructs show increased invasion in 4-OHT-treated conditions compared to control. Altogether these results suggest a role of $\mathrm{p}$ YBX1 in promoting invasion.

MIR31HG knock-down inhibits YBX1-RSK interaction. We next examined whether $M I R 31 H G$ might have an impact on YBX1 phosphorylation. We performed cellular fractionation to analyse the localization of phosphorylated YBX1 in senescent cells and in senescent cells where MIR31HG was depleted. Interestingly, we observed that upon MIR31HG knock-down p-YBX1 is reduced in the cytoplasm (Fig. 6a, b), suggesting a role for MIR31HG in the phosphorylation process of YBX1. Several cytoplasmic lncRNAs have been shown to act as scaffolds for bringing molecules into close proximity. In order to analyse whether MIR31HG was binding both YBX1 and its kinase RSK, we performed native RIP using GFP-tagged version of RSK. We could not detect RSK binding to MIR31HG (Supplementary Fig. 6a, b). To further analyse the role of MIR31HG in the interaction of YBX1 with its kinase RSK, we performed proximity ligation assays (PLAs) using antibodies against total YBX1 and total RSK. Importantly, the interaction was higher in senescence compared to control (Fig. 6c, d). Interestingly, MIR31HG knockdown reduced the level of interaction confirming our hypothesis that MIR31HG mediates YBX1 interaction with its kinase RSK during OIS (Fig. 6c, d). In order to corroborate this result, we have performed in vitro kinase assays using recombinant RSK and recombinant $\mathrm{YBX} 1$, and observed that YBX1 is phosphorylated in a RSK-dependent manner (Supplementary Fig. 6c). We could detect RSK auto-phosphorylation as previously shown ${ }^{51}$
(Fig. 6e and Supplementary Fig. 6c). Addition of in vitrotranscribed MIR31HG resulted in a moderate but significant increase in p-YBX1 phosphorylation compared to ND4 and Mut3, lacking YBX1-binding site (Fig. 6e). To demonstrate that the interaction between YBX1 and MIR31HG is responsible for YBX phosphorylation, we created BJ ER:BRAF cell lines expressing doxycycline-inducible MIR31HG constructs WT, Mut5 and Mut3 (Supplementary Fig. 6d). Interestingly, overexpression of WT and Mut5 transcripts showed increased levels of p-YBX1 compared to an empty cell line and Mut3 overexpression, which was unable to bind MIR31HG (Figs. 4k and 6f, g). These results confirm that the interaction between MIR31HG and YBX1 facilitates its phosphorylation.

\section{Discussion}

The SASP is a hallmark of senescent cells and responsible for mediating the patho-physiological effects in the surrounding tissues. For a long time, efforts in the field have been focused on trying to induce senescence in cancer cells in order to prevent cancer progression ${ }^{7,52,53}$. In contrast hereto, more recent reports have shown that targeting senescent cells strongly improve agerelated diseases ${ }^{20,54,55}$. Although recent work has extended our knowledge of the signalling network upstream the transcriptional induction of the SASP components ${ }^{56-60}$, the complexity and diversity of the SASP suggest that additional regulators might be involved. It is crucial to acquire further knowledge of the detailed mechanism to be able to design therapies for cancer, inflammation and aging treatment. Here, we contribute to understanding the SASP regulation by describing the molecular mechanism by which the lncRNA MIR31HG regulates a subset of the SASP components during BRAF-induced senescence by modulating $I L 1 A$ translation. It is known that most of the SASP components are regulated at the transcriptional level, although a small fraction may additionally be regulated by post-transcriptional mechanisms ${ }^{35,57}$. In this study, we focus on the senescence process initiated following the expression of a mutated BRAF. This is of importance as somatic mutations in BRAF occur in approximately $7 \%$ of human cancer $^{61}$. We observed that MIR31HG expression is higher in thyroid and colorectal cancer tumour samples harbouring $B R A F$ mutations, as compared to $B R A F$ wild type, suggesting the relevance of this lncRNA in cancer.

We find that the secretome from BJ ER:BRAF senescent cells and BJ ER:BRAF MIR31HG knock-down senescent cells show differences in the levels of key SASP components. Whereas most 
a

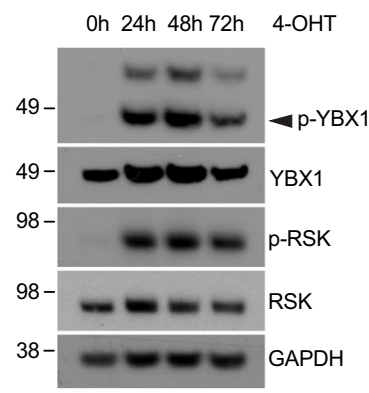

b

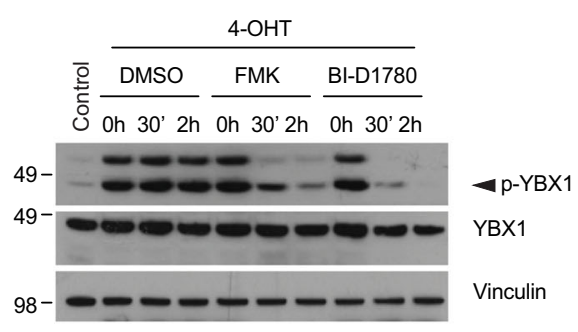

C

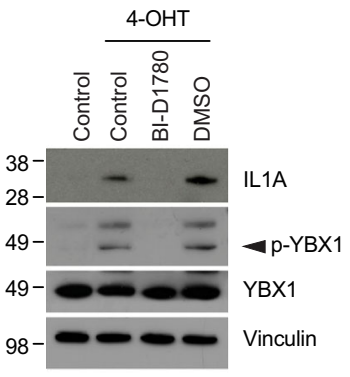

d

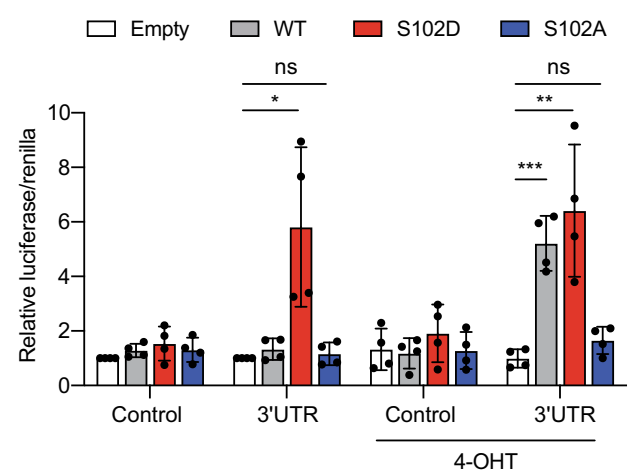

e

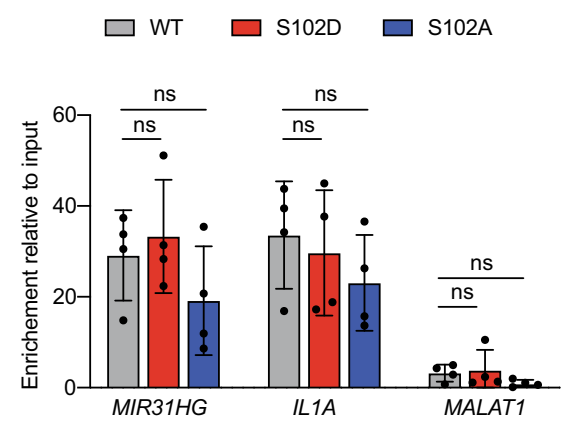

f

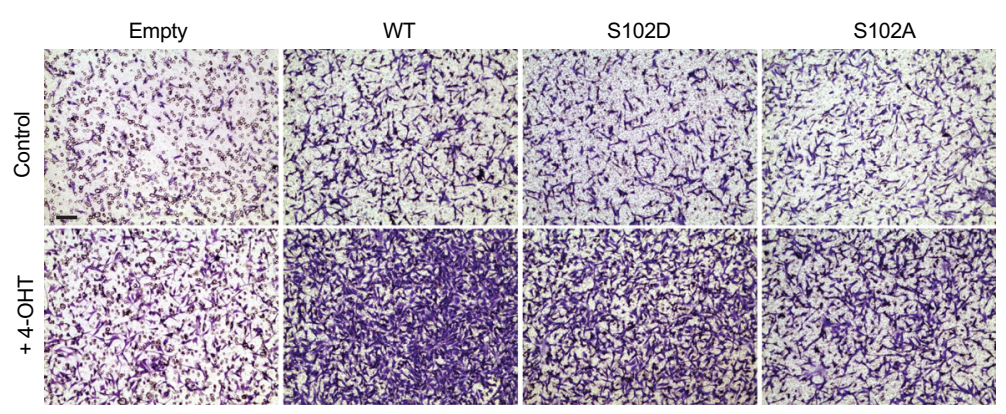

g

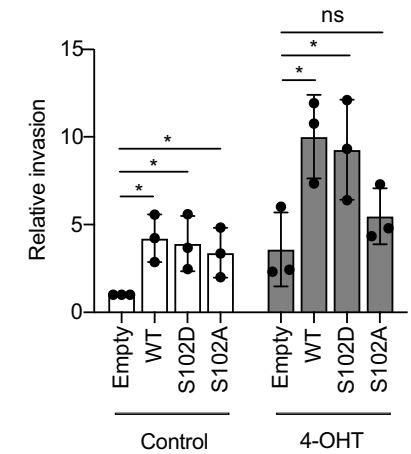

Fig. 5 Phosphorylated YBX1 induces IL1A translation. a Western blot for $p$-RSK1, RSK1, p-YBX1, total YBX1 and Vinculin in BJ ER:BRAF cells treated with 1 $\mu \mathrm{M} 4-\mathrm{OHT}$ for the indicated time. Molecular weight marker is shown in $\mathrm{kDa}(n=3)$. b Western blot for $\mathrm{p}-\mathrm{YBX} 1$, total YBX1 and Vinculin in BJ ER:BRAF cells untreated (control) or treated with $1 \mu \mathrm{M} 4-\mathrm{OHT}$ and the indicated inhibitor at $1 \mu \mathrm{M}$ for the indicated time. DMSO is used as vehicle control. Molecular weight marker is shown in $\mathrm{kDa}(n=3)$. c Western blot for $\mathrm{p}-\mathrm{YBX} 1$, total YBX1, IL1A and Vinculin in BJ ER:BRAF cells untreated (control) or treated with 1 $\mu \mathrm{M} 4-\mathrm{OHT}$ and BI-D1780 at $1 \mu \mathrm{M}$ for $72 \mathrm{~h}$. Molecular weight marker is shown in $\mathrm{kDa}(n=4)$. d Relative luciferase measurement in BJ ER:BRAF cells expressing a doxycycline-induced empty, wild type (WT), mutant S102A or mutant S102D versions of YBX1 were transfected with a siRNA against YBX1 and reporter constructs pGL3-promoter (control) or pGL3-promoter-3'UTR (3'UTR) containing the 3'UTR of IL1A mRNA and treated with ethanol (control) or with $1 \mu \mathrm{M} 4-\mathrm{OHT}$ for $48 \mathrm{~h}$. The graph shows the Luciferase values normalized to renilla relative to the empty cell line in the absence of 4-OHT set as 1 ( $n$ =4). e RIP analysis using a GFP-tagged version of WT YBX1, S102A mutant or S102D mutant in formaldehyde crosslinked cells induced with doxycycline and treated with $1 \mu \mathrm{M} 4-\mathrm{OHT}$ for $72 \mathrm{~h}$. The graph shows YBX1 binding to MIR31HG, IL1A and MALAT as a negative control. The results are shown as the percentage of input relative to an empty GFP cell line treated in the same conditions $(n=4)$. $\mathbf{M D A}-\mathrm{MB}-231$ invading cells through a matrigel membrane in contact with the CM from BJ ER:BRAF cells expressing a doxycycline-induced empty, wild type, mutant S102A or mutant S102D treated for 72 h with ethanol (Control) or $1 \mu \mathrm{M} 4-\mathrm{OHT}$. Representative images are shown in the figure. Scale bar: $50 \mu \mathrm{m}$. $\mathbf{g}$ Quantification of the invading cells from (f) relative to control ethanol-treated cells $(n=3)$. All statistical significances were calculated using two-tailed Student $t$-tests, ${ }^{\star} p<0.05 ;{ }^{* \star} p<0.01 ;{ }^{\star \star \star} p<0.001 ;$ ns nonsignificant. All error bars represent means \pm s.d. Source data are provided as a Source Data file.

of the genes deregulated at the transcription level are also altered at the protein level, a small proportion is regulated only at RNA or protein level. This, together with the comparable polysome distribution profiles of these cell lines, suggests no changes in global translation upon MIR31HG depletion. Interestingly, IL1A, an upstream regulator of the SASP, is reduced at the protein level following MIR31HG knock-down whereas the mRNA level is not significantly altered. No IL1A was detected in the conditioned media by mass spectrometry or by ELISA, likely due to the fact that IL1A remains attached to the membrane during OIS as previously described ${ }^{34}$. In our cellular system addition of hr-IL1A induces the transcription of several cytokines and instigates the SASP. Intriguingly, it also rescues the decreased transcription of SASP components caused by MIR31HG depletion during BRAF- 
a

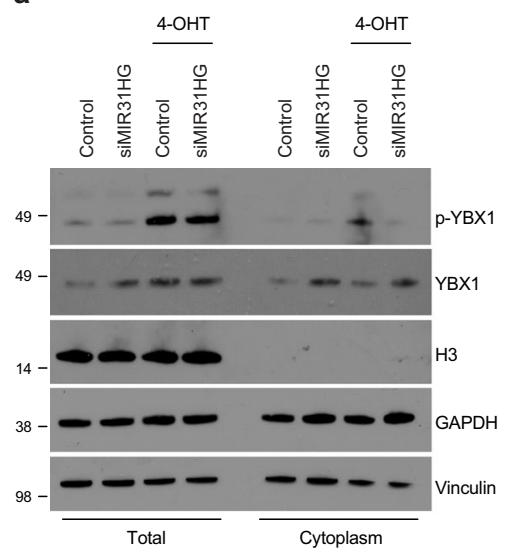

d

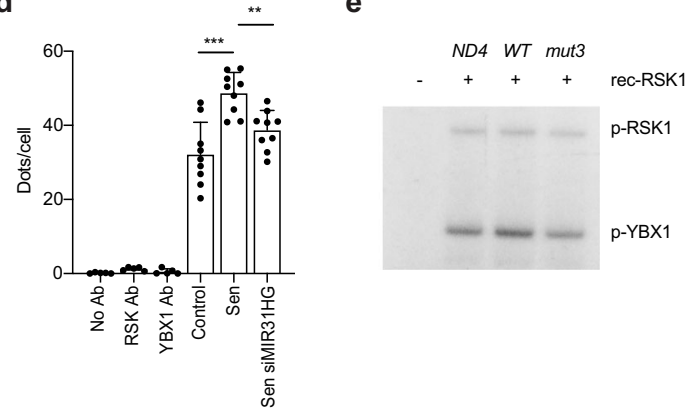

b

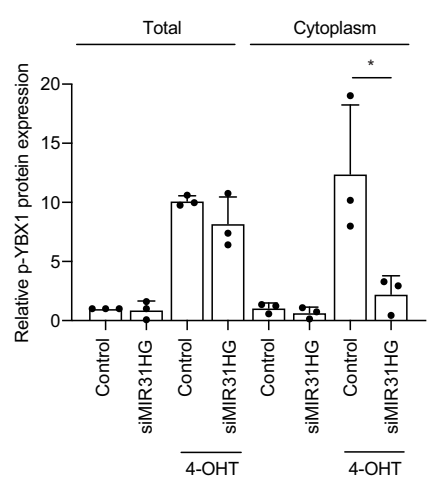

C

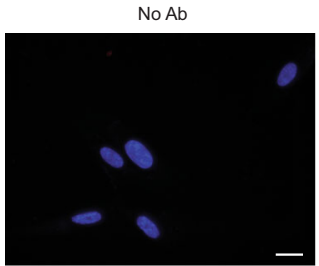

Sen
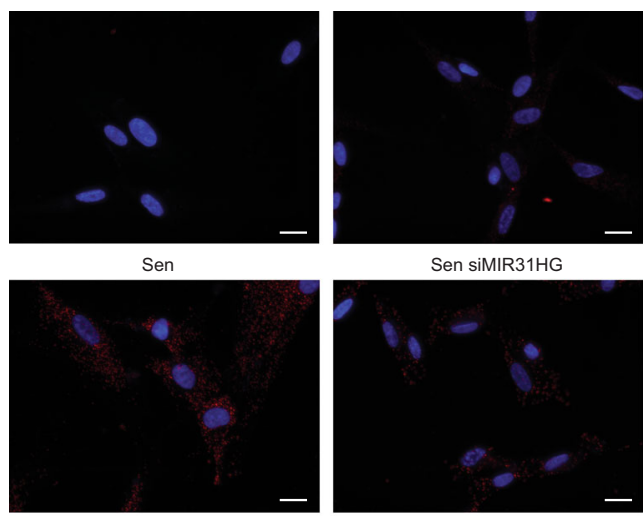

Sen siMIR31HG

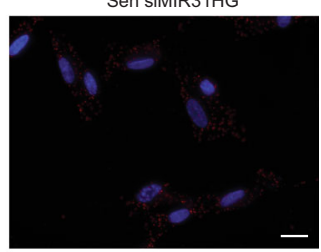

f
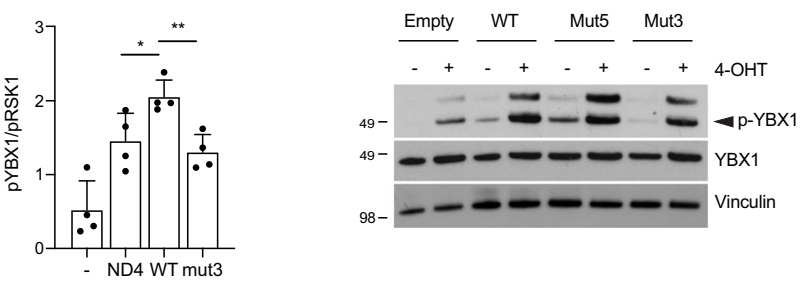

g

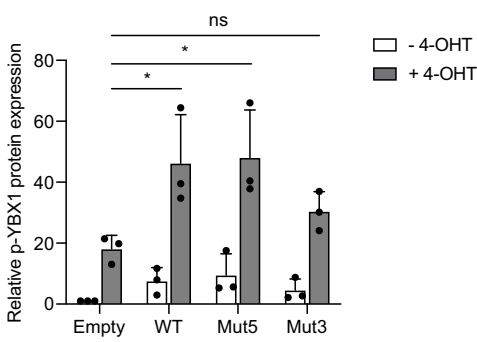

h

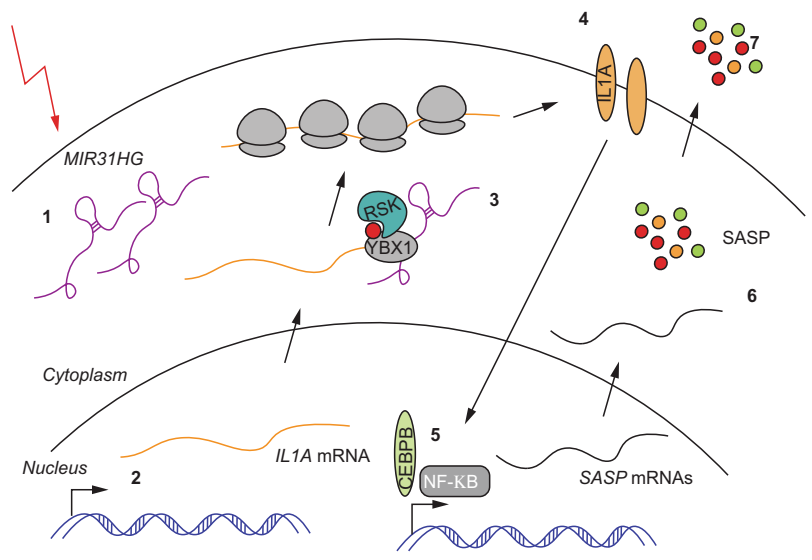

Fig. 6 MIR31HG promotes YBX1 phosphorylation by facilitating YBX1 interaction with its kinase RSK. a Western blot analysis for $p-Y B X 1$, total YBX1, GAPDH and H3 in total and cytoplasmic fractions of BJ ER:BRAF cells (Control or siMIR31HG1-2) treated with ethanol (Control) or $1 \mu \mathrm{M} \mathrm{4-OHT} \mathrm{for} 72 \mathrm{~h}$ ( $n$ =3). $\mathbf{b}$ Quantification of the $\mathrm{PYBX} 1$ band intensities relative to total $Y B X 1$ and Vinculin from three independent experiments. $\mathbf{c}$ PLA representative images showing the interaction (red dots) between YBX1 and RSK in BJ ER:BRAF cells (Control or siMIR31HG1) were treated with ethanol (Control) or $1 \mu \mathrm{M} 4-\mathrm{OHT}$ for $72 \mathrm{~h}$. DAPI staining (blue) shows the nucleus. d Quantification of the number of interactions (dots) per cell in the conditions indicated in a representative experiment from four independent replicates $(n=4)$. Scale bar: $20 \mu \mathrm{m}$. e Left, in vitro kinase experiment incubating recombinant YBX1 in the presence of ${ }^{32} \mathrm{P}$-ATP and recombinant RSK1 in the presence of the indicated in vitro-transcribed RNA, run in 4-12\% NuPAGE Bis-Tris gel and exposed to an Amersham Hyperfilm ECL film. Right, quantification of the band intensities represented as p-YBX1 related to $p$-RSK $(n=4)$. $\mathbf{f}$ Western blot for $p$-YBX1, total YBX1 and Vinculin in BJ ER:BRAF cells expressing a doxycycline-induced empty, MIR31HG WT, Mut3 or Mut5 treated for $36 \mathrm{~h}$ with ethanol (Control) or 1 $\mu \mathrm{M}$ 4-OHT. $\mathbf{g}$ Quantification of the $\mathrm{p}-\mathrm{YBX} 1$ band intensities relative to total YBX1 and Vinculin $(n=3)$. $\mathbf{h}$ Scheme of the working model: $(1)$ During OIS MIR31HG is induced and locates in the cytoplasm. (2) At the same time, transcription of ILIA mRNA is induced. (3) IL1A mRNA is exported to the cytoplasm where it interacts with YBX1. MIR31HG facilitates YBX1 interaction with the kinase RSK promoting its phosphorylation which in turns promotes IL1A translation. (4) IL1A signalling induces the transcription of other SASP mRNAs through CEBPB and NF- $\kappa$ B. (5) These RNAs will be translated in the cytoplasm and the SASP components will be secreted (6). Statistical significance was calculated using two-tailed Student's $t$-tests, ${ }^{\star} p<0.05$; ${ }^{\star \star} p<0.01$; ${ }^{\star \star \star} p<0.001$. Error bars represent means \pm s.d. Source data are provided as a Source Data file.

induced senescence. These results strongly support the idea of MIR31HG regulating IL1A as an upstream regulator of the SASP transcriptional program. Work from the Campisi lab has demonstrated that the translation of IL1A during RAS-induced senescence is regulated by $\mathrm{mTOR}^{35}$. Although the $\mathrm{mTOR}$ pathway is increased in our OIS model, it is not altered in MIR31HG knock-down conditions. Instead, we found the lncRNA MIR31HG to affect IL1A translation through YBX1. Endogenous MIR31HG pull down and subsequent validations by RIP and EMSA confirm that YBX1 is a MIR31HG-binding 
partner. Importantly, YBX1 depletion mimics the MIR31HG knock-down phenotype in BRAF-induced senescence. This includes the reduced translation of IL1A and therefore the downregulation of downstream SASP components at RNA level, such as CXCL1, IL8 or IL6 among others. Recent work has shown that YBX1 prevents cytokine translation in cycling keratinocytes by binding their $3^{\prime}$ UTR. In these studies, YBX1 knock-down results in increased translation of several cytokines and therefore induction of senescence ${ }^{38}$. Knock-down of YBX1 in cells subjected to BRAF-induced senescence resulted in reduced RNA levels of most of the cytokines previously annotated as SASP components ${ }^{13}$. Interestingly, in BRAF-induced senescence we observe that YBX1 binds a high fraction of the IL1A mRNA while binding other cytokines to a lesser extent. YBX1 binds AU-rich motifs present in the $3^{\prime}$ UTR of cytokine mRNAs ${ }^{38,62}$, which is consistent with our IL1A $3^{\prime}$ UTR luciferase reporter assays. However, the stronger binding of YBX1 to IL1A mRNA compared to other cytokines show some degree of specificity towards IL1A mRNA. The mechanism underlying this specificity remains unknown. In a recent study, Dominguez et al. ${ }^{63}$ determined the importance of contextual features in RNA recognition by RBPs. Perhaps RNA secondary structures, the flanking nucleotide composition or the proximity to other RNA-binding proteins might be influencing the binding of YBX1 to the IL1A mRNA.

We observe an increase in $\mathrm{p}-\mathrm{YBX}^{\mathrm{S} 102}$ in BRAF-induced senescence and, importantly, $\mathrm{p}-\mathrm{YBX}^{\mathrm{S} 102}$ is reduced in the cytoplasm upon MIR31HG knock-down. Our results indicate that this post-transcriptional modification of YBX1 is involved in promoting IL1A translation during BRAF-induced senescence through its $3^{\prime} \mathrm{UTR}$, which could explain the previously reported opposite roles of YBX1 in cytokine translation ${ }^{38}$. The role of $\mathrm{p}$ YBX1 in translation remains to be fully understood. It is known that YBX1 binds the mRNA cap structure by displacing the eukaryotic translation factor $4 \mathrm{E}$ (eIF4E) and eIF4G and hence promotes translational repression ${ }^{44,64} \cdot \mathrm{p}-\mathrm{YBXI}^{\mathrm{S} 102}$, on the other hand, binds the mRNA cap structure less tightly allowing translation of repressed mRNAs ${ }^{46}$. However, not much is known about its role in promoting translation. Our luciferase reporter assay indicates that during senescence, $\mathrm{p}-\mathrm{YBX} 1^{102}$ may have a role in promoting IL1A translation through the $3^{\prime} \mathrm{UTR}$ since the phosphomutant $\mathrm{YBX1}^{\mathrm{S} 102 \mathrm{~A}}$ fails to induce luciferase induction. Importantly, invasion is reduced when overexpressing $\mathrm{YBX}^{\mathrm{S} 102 \mathrm{~A}}$ as compared to $\mathrm{p}-\mathrm{YBX} 1^{102}$ and $\mathrm{YBX} 1^{\mathrm{S} 102 \mathrm{D}}$. Although we have observed increased invasion upon YBX1 overexpression independently on its phosphorylation status, confirming previous findings of YBX1 involved in metastasis and invasion ${ }^{49,65,66}$, this result suggests that the YBX1 reduced phosphorylation is, at least, partly responsible for the SASP-induced invasion observed in MIR31HG-depleted senescent cells. Mutation of S102 did not alter YBX1 binding capability to IL1A or other mRNAs, consistently with previous reports demonstrating that phosphorylation at S102 does not affect the general RNA binding capacity of YBX1 (ref. ${ }^{44}$ ). Phosphorylation of translation factors are determining events occurring during translation regulation ${ }^{67}$ and perhaps $\mathrm{p}$-YBX1 is involved in differentially recruiting other translation factors with a role in IL1A mRNA translational regulation. Further phospho-proteomic studies would help to address this question. We cannot exclude that phosphorylation at other residues occur during senescence. In fact, S165 and S176 have been shown to activate NF- $\mathrm{kB}$ signalling ${ }^{68,69}$. It would be interesting to investigate whether these modifications have any impact in senescence or in translation regulation.

LncRNAs can modulate post-transcriptional modifications of proteins $^{70-73}$. Our results suggest that during BRAF-induce senescence RSK appears to be the main kinase responsible for YBX1 phosphorylation. PLA experiments show an increase in
RSK-YBX1 interaction during OIS correlating with an increased level of p-YBX1. Despite at a lower level, the presence of interaction in proliferating conditions suggests that the interaction may occur without BRAF induction. The signalling cascade activated during OIS might be necessary to phosphorylate YBX1 at least at S102. We cannot exclude that RSK phosphorylates other residues in proliferating cells. Nevertheless, our results indicate that the interaction between MIR3HG and YBX1 is important for the phosphorylation of YBX1 by RSK and its role in senescence, when the lncRNA is expressed and predominantly located in the cytoplasm ${ }^{28}$.

YBX1 is a very abundant protein whereas MIR31HG is expressed at low levels. The stoichiometry does not correlate with a static model in which MIR31HG acts as a platform for YBX1. Moreover, we do not detect MIR31HG directly binding RSK, likely excluding a role for MIR31HG as scaffold bridging together YBX1 and its kinase. Our results suggest that MIR31HG-YBX1 is a dynamic interaction that might infer an optimal conformation of YBX1 to facilitate its phosphorylation. Although the in vitro kinase experiments support this model, structural studies or more exhaustive phospho-proteomic analysis would be required to confirm this hypothesis.

The SASP has been reported to either limit or promote tumour progression. Dissociation of the good and bad sides of the SASPs is difficult since many of its components can have both roles depending on the cellular context ${ }^{14}$. Besides, many of the senescence effectors are activated by the same pathways that activate the SASP. Therefore, the identification of factors that can affect the SASP without altering the tumour-suppressive effects associated with senescence is a promising strategy for senescencerelated therapies. Several reports have described factors that can uncouple the senescence growth arrest from the SASP $35,36,57,59$. Here, we identify an IncRNA that, when located in the cytoplasm during OIS, is responsible for the production of a distinct subset of SASP components. Its depletion during OIS leads to a decrease of interleukins, chemokines and other factors preventing invasion in vitro without reverting growth arrest. Interestingly, we have previously described a mechanism for the nuclear MIR31HG in proliferating cells in repressing $\mathrm{p} 16^{\mathrm{INK} 4 \mathrm{~A}}$ expression by recruiting polycomb group proteins ${ }^{28}$. Altogether, our results suggest that the lncRNA MIR31HG has a dual role in inducing and buffering senescence depending on the cellular localization, which highlights the complexity of the regulation of senescence and the SASP. Interestingly, MIR31HG has been reported to be upregulated in different types of cancer ${ }^{74-76}$. The fact that depletion of MIR31HG induces p16 expression without activation of a SASP response $^{28}$ and decreases pro-invasive factors during SASP induction makes it an interesting target for therapeutic purposes. Inhibition of MIR31HG as well as other anti-SASP therapies could be potentially used to ameliorate the detrimental effects of senescence cells.

\section{Methods}

Cell cultures, treatments, siRNA transfections. The human diploid cell lines TIG3 and BJ were immortalized using pbabe-hTERT and pMSCV-ER:B-RAF retroviral constructs. Hek-293T were transfected using calcium phosphate transfection with $10 \mu \mathrm{g}$ of each plasmid. Forty-eight hours later, virus were harvested and filtered through a $0.45-\mu \mathrm{m}$ pore filter. Confluent BJ and TIG3 cells were transduced using $1 / 3$ of the viral supernatant and $8 \mu \mathrm{g} / \mu \mathrm{l}$ polybrene. Twenty-four hours post-transduction the cells were selected with $50 \mu \mathrm{g} / \mathrm{ml}$ neomycin (h-TERT) and $5 \mu \mathrm{g} / \mathrm{ml}$ blasticidine (B-RAF).

BJ ER:BRAF, TIG3:BRAF, BJ wild type (WT), IMR90 and MDA-MB-231 cells were maintained in Dulbecco's modified Eagle's medium (Invitrogen)

supplemented with $10 \%$ foetal bovine serum (FBS) (Hyclone) and penicillin/ streptomycin (Invitrogen).

BJs and TIG3 were authenticated using IDEXX services (IMPACT II PCR Profile; CellCheck 9-human (9 Marker STR Profile and Inter-species Contamination Test). MDA-MD-231 were obtained from Janine Erler (BRIC, 
University of Copenhagen) and IMR90 from Maite Huarte (CIMA, Pamplona, Spain). Senescence was induced by treatment with $1 \mu \mathrm{M}$ 4-hydroxytamoxifen (4OHT, Sigma) $24 \mathrm{~h}$ after cell seeding for at least $48 \mathrm{~h}$ (unless otherwise indicated). siRNA oligonucleotides were transfected at a final concentration of $50 \mathrm{nM}$ by reverse transfection using RNAiMAX (Invitrogen) according to the manufacturer's instructions for 48 or $72 \mathrm{~h}$. The siRNAs sequences are listed in Supplementary Table 1. In case of senescence induction, $1 \mu \mathrm{M} 4$-OHT was added $24 \mathrm{~h}$ after transfection to fresh media for $48 \mathrm{~h}$ for RNA analysis or $72 \mathrm{~h}$ for protein analysis. RSK inhibitors, BI-D1780 (Axon 1528) and FMK (Gift from Morten Frodin), were used at $10 \mu \mathrm{M}$ for the time indicated in each experiment.

Doxycicline-inducible cell lines. YBX1-GFP and RSK-GFP overexpressing cell lines: To generate lentiviral constructs, we cloned the coding sequence of YBX1 amplified from cDNA, into the inducible vector pLVX-TetOne Puro Vector (Clontech) that already contained GFP-fusion protein. We use In-Fusion HD Cloning designing primers according to the manufacturer's indications (see primer sequences in Supplementary Table 1).

For the lentiviral production, HEK293T cells were transfected using lipofectamine 2000 (Lifetechnologies) with $7 \mu \mathrm{g}$ of pLVX-YBX1-GFP or pLVXempty-GFP, together with $6 \mu \mathrm{g}$ of VsVg and $5 \mu \mathrm{g}$ Pax8 viral plasmids. After $48 \mathrm{~h}$ supernatants containing the viral particles were filter through a $0.45 \mu \mathrm{m}$ filter. Confluent BJ ER:BRAF cells were then transduced with $1 / 3$ of the viral supernatant and $8 \mu \mathrm{g} / \mu \mathrm{l}$ polybrene. Twenty-four hours post-transduction the cells were selected with $1 \mu \mathrm{g} / \mathrm{ml}$ puromycin. Cells were maintained in tetracycline-free tested serum (Clontech). For the expression of YBX1, $100 \mathrm{ng} / \mathrm{ml}$ doxycycline was used for $72 \mathrm{~h}$ unless otherwise indicated. To generate the phosphomutant (S102A) and phosphomimic (S102D) versions of the protein, directed mutagenesis was performed using QuikChange II XL Site-Directed Mutagenesis Kit (Agilent) directly from the pLVX-YBX1-GFP construct. Primers with the respective mutations were designed according to the manufacturer's indications (see sequences in Supplementary Table 1). The pLVX-RSK-GFP cell line was generated as described for YBX1, amplifying the coding sequence from cDNA with specific primers (sequences in Supplementary Table 1).

MIR31HG overexpressing cell lines: To generate the MIR31HG-overexpressing cell lines we cloned the full-length MIR31HG (NR_027054.2), the Mutant 3 or the Mutant 5 sequences into the inducible vector pLVX-TetOne Puro Vector (Clontech) as described above. Primers are shown in Table 1.

MIR31HG expression analysis in tumour samples. Gene expression (RNAseq) and somatic mutation data for tumours in The Cancer Genome Atlas (TCGA PanCancer) were downloaded from UCSC Xena platform ${ }^{77}$. Thyroid carcinoma (THCA) and colorectal adenocarcinoma (COAD \& READ) were used for analysis because these tumours have high frequency of BRAF mutations $(>10 \%)$ and also express MIR31HG (CRC BRAF_wt $=309$; CRC BRAF_mutant $=49$; THCA BRAF_mutant $=290$; THCA BRAF_wt $=199$ ). Expression values for all the samples were converted to $\log 2(\mathrm{fpkm}+1)$ unit. Wilcoxon test was performed to compare the expression differences in the BRAF mutant and BRAF wild-type tumours, using $\mathrm{R}$.

RNA extraction and qRT-PCR analysis. Total RNA was isolated using Trizol reagent (Invitrogen), treated with TURBO DNase (Ambion, Lifetechnologies) and reverse transcribed using TaqMan Reverse Transcription kit (Applied Biosystems) with random hexamer primers. Quantitative real-time PCRs were performed using Syber Green PCR Fast PCR Master Mix 2x and Step One Plus real-time PCR and software v2.3 (Applied Biosystems). The housekeeping genes HPRT1 and RPLP0 were used for normalization of qRT-PCR data, unless otherwise stated.

To calculate the number of molecules per cell, MIR31HG was in vitro transcribed (see In vitro transcription and labelling). The concentration of the transcript was measured by $A_{260}$ values and converted to the number of copies using the molecular weight of the RNA. Dilutions of this transcript were retrotranscribed as described above and the complementary DNA was used as standard curve for qPCR. The primers used for qPCR are listed in Supplementary Table 1.

Western blot analysis. Cells were seeded and reverse transfected in six-well plates (NUNC). In case of senescence, cells were treated the following day with $1 \mu \mathrm{M} \mathrm{4-}$ OHT. After $72 \mathrm{~h}$ cells were harvested, washed once with phosphate-buffered saline (PBS) and the pellets lysed in RIPA buffer ( $150 \mathrm{nM} \mathrm{NaCl}, 0.1 \%$ sodium deoxycholate, $0.1 \%$ sodium dodecyl sulfate, $50 \mathrm{~mm}$ Tris- $\mathrm{HCl}$ (pH 8 ), $1 \mathrm{mM}$ EDTA) containing protease inhibitors (Complete Mini Protease Inhibitor Cocktail; Roche Applied Science). Proteins were separated by electrophoresis in $4-12 \%$ NuPAGE Bis-Tris gels (Invitrogen) and transferred to nitrocellulose membranes (Amersham). The antibodies used for western blotting are listed in Supplementary Table 2.

Conditioned media. To generate conditioned media, the cells transfected and treated as indicated were growing in serum-free growth media for $24 \mathrm{~h}$. The media was filtered through a $0.45-\mu \mathrm{m}$ filter, centrifuged at $500 \times g$ for $5 \mathrm{~min}$ and placed on the corresponding recipient cells for the time indicated in each experiment.
Secretome analysis. The CM for proteomics analysis was harvested from $6 \mathrm{~cm}$ plates as indicated above. CM was concentrated using Centricon (Milipore) $3 \mathrm{kDa}$ filter, precipitated by TCA and washed in acetone. Protein pellets were resuspended in $6 \mathrm{M} \mathrm{GndHCl} \mathrm{in} 10 \mathrm{mM}$ Tris/ $\mathrm{HCl} \mathrm{pH} 8.0$ with $2 \mathrm{mM}$ DTT and incubated at $56^{\circ} \mathrm{C}$ for $30 \mathrm{~min}$. In-solution digestion was performed after sample dilution with $50 \mathrm{mM}$ TEAB using $250 \mathrm{ng}$ of LysC (Wako) (at $2 \mathrm{M} \mathrm{GndHCl}$ ) and followed by $500 \mathrm{ng}$ of trypsin (Promega) (at $0.6 \mathrm{M} \mathrm{GndHCl}$ ). Reduced, alkylated and acidified peptides were desalted on $100 \mu \mathrm{l}$ C18 stage tips (Thermo Fisher Scientific) and subjected to LC-MS/MS analysis.

Tryptic peptides were identified by LC-MS using an EASY-nLC 1000 (Thermo Fisher Scientific) coupled to a Q Exactive HF (Thermo Fisher Scientific) equipped with a nanoelectrospray ion source. Peptides were separated on an in-house packed column of ReproSil-Pur C18-AQ, $3 \mu \mathrm{m}$ resin (Dr Maisch, GmbH) using a 90-min gradient of solvent A ( $0.5 \%$ acetic acid) and solvent B ( $80 \%$ acetonitrile in $0.5 \%$ acetic acid) and a flow of $250 \mathrm{nl} / \mathrm{min}$. The mass spectrometer was operated in positive ion mode with a top 12 data-dependent acquisition, a resolution of 60,000 (at $400 \mathrm{~m} / \mathrm{z}$ ), a scan range of $300-1700 \mathrm{~m} / z$ and an AGC target of $3 \mathrm{e} 6$ for the MS survey. MS/MS was performed at a scan range of $200-2000 \mathrm{~m} / z$ using a resolution of 30,000 (at $400 \mathrm{~m} / z)$, an AGC target of 1e5, an intensity threshold of $1.0 \mathrm{e} 5$ and an isolation window of $1.2 \mathrm{~m} / z$. Further parameters included an exclusion time of $45 \mathrm{~s}$ and a maximum injection time for survey and MS/MS of 15 and $45 \mathrm{~ms}$, respectively.

The raw files obtained from LC-MS were processed using the MaxQuant software 72 version 1.5.3.30. Peak lists were searched against the human UniProt database using the Andromeda search engine incorporated in MaxQuant with a tolerance level of $7 \mathrm{ppm}$ for $\mathrm{MS}$ and $20 \mathrm{ppm}$ for $\mathrm{MS} / \mathrm{MS}^{78}$. Trypsin was chosen as digestion enzyme with max 2 missed cleavages allowed. Variable modifications were set to methionine oxidation, protein $\mathrm{N}$-terminal acetylation, deamidation of asparagine and glutamine. Carbamidomethylation of cysteine was set as fixed modification and other parameters were kept as default.

Statistical analysis was conducted in R environment (https://www.r-project.org) using DEP (v. 1.8.0) bioconductor package for proteomics analysis, and visualizations were made using the ggplot $2 \mathrm{R}$ package $\mathrm{e}^{79}$. Imputation of missing data was performed using MinProb setting based on minimal intensity values observed for each sample.

Crystal violet staining. Cells were seeded and reverse transfected in 6-well or 12well plates (NUNC). 24, 48 and $72 \mathrm{~h}$ after transfection or treatment cells were washed twice in PBS and fixed with $10 \%$ formalin for $10 \mathrm{~min}$ and stained with $0.1 \%$ crystal violet solution for $30 \mathrm{~min}$. Excess crystal violet stain was removed by several washes with water. The plates were allowed to dry and crystal violet was extracted by the addition of $10 \%$ acetic acid. The amount of crystal violet staining was quantified by measurement of the absorbance at $570 \mathrm{~nm}$.

Senescence-associated $\boldsymbol{\beta}$-galactosidase staining. Cells were seeded and transfected in 12-well plates (NUNC). At $72 \mathrm{~h}$ post-transfection they were fixed and stained using the $\beta$-galactosidase staining kit (Cell Signaling) according to the manufacturer's protocol.

Invasion assay. In all, $50 \mu \mathrm{l}$ of $0.5 \mu \mathrm{g} / \mathrm{ml}$ Matrigel LDEV-Free(Corning) was added to the transwell (Croning). Four hundred microliters of the desired CM was placed at the bottom of the transwell with $8.0 \mu \mathrm{m}$ pore size. In total, 50,000 MDA/MB231 cells were resuspended in $200 \mu \mathrm{l}$ DMEM without FBS and place on top of the transwell. After $48 \mathrm{~h}$ cells across the matrigel membrane were washed in PBS and fixed in cold $70 \%$ ethanol for $15 \mathrm{~min}$ and stained using crystal violet staining as indicated above.

Cell fractionation. Cells were grown in $15 \mathrm{~cm}$ dishes (NUNC). Nuclear/cytoplasmic fractionation was performed using Nuclei EZ Lysis Buffer (Sigma) following the manufacturer's protocol.

Immunofluorescence. Cells were seeded on multichamber slides (Nunc) and transfected or treated. Seventy-two hour cells were washed with PBS $1 \times$ and fixed in $4 \%$ paraformaldehyde (PFA) (Sigma) for $15 \mathrm{~min}$. The cells were permeabilized using $0.1 \%$ Triton X-100 in PBS (Sigma) following antibody incubation. Images were taken using a Zeiss fluorescence microscope and ZenPro software 2011. Antibodies and dilutions are listed in Supplementary Table 2.

Chromatin immunoprecipitation. Cells were fixed with $1 \%$ formaldehyde for $10 \mathrm{~min}$. Crosslinking was arrested by adding glycine $(0.125 \mathrm{M})$ for $5 \mathrm{~min}$ at room temperature. The cells were subsequently harvested in SDS lysis buffer $0.5 \%$ SDS $100 \mathrm{mM} \mathrm{NaCl}, 50 \mathrm{mM}$ Tris-Cl pH 8.1, $5 \mathrm{mM}$ EDTA pH 8.0, protease inhibitor mixture Complete [Roche], and $1 \mathrm{mM}$ phenylmethylsulfonyl fluoride. Nuclei were pelleted and resuspended in IP buffer (2 volumes SDS lysis buffer: 1 volume TritonX buffer [100 mM Tris-Cl, pH 8.6, $100 \mathrm{mM} \mathrm{NaCl}, 5 \mathrm{mM}$ EDTA pH 8.0, 5\% Triton $\mathrm{X}-100])$. The lysates were sonicated using BIORUPTOR sonicator for 12 cycles of $30 \mathrm{~s}$ and centrifuged at maximum speed. The sheared chromatin was diluted to $1 \mathrm{ml}$ with IP buffer and precleared with salmon sperm DNA/recombinant protein 
A agarose (Thermo Fisher Scientific) for $2 \mathrm{~h}$. One per cent of the sample was used as the input control, and the remaining precleared chromatin was incubated overnight with $10 \mu \mathrm{g}$ of antibody (see Supplementary Table 5) by incubation with salmon sperm DNA/protein A agarose (50\% slurry) and centrifugation. The bead pellets were washed in low- or high-salt conditions $(0.1 \%$ SDS, $1 \%$ Triton X-100, $2 \mathrm{mM}$ EDTA pH 8.0, $20 \mathrm{mM}$ Tris- $\mathrm{HCl} \mathrm{pH} 8.0$, and $150 \mathrm{mM}$ [low]/500 mM [high] $\mathrm{NaCl}$ ) followed by two washes with Tris-EDTA buffer. Elution buffer $(0.1 \%$ SDS, $0.1 \mathrm{M} \mathrm{NaHCO}_{3}$ ) was added to the samples and the crosslinking was reverted by incubation at $68^{\circ} \mathrm{C}$ overnight. Samples were incubated $1 \mathrm{~h}$ at $37^{\circ} \mathrm{C}$ with RNAse A (Sigma) and $45 \mathrm{~min}$ at $50^{\circ} \mathrm{C}$ with proteinase $\mathrm{K}$ (Ambion). The DNA was purified using Minelute PCR Purification Kit (Qiagen) and then amplified by qPCR using primers listed in Supplementary Table 1.

RNA sequencing and bioinformatic analysis. RNA integrity was confirmed on an Agilent 2100 Bioanalyzer using Agilent RNA 6000 Nano kit (Agilent Technologies). RNA-seq libraries were prepared from $2 \mu \mathrm{g}$ total RNA with CATS mRNA-seq Kit (with polyA selection) v2 x24 (Diagenode) according to the manufacturer's protocol. Concentrations of the libraries were measured using the Qubit fluorometer (Invitrogen) and fragment size was assessed on an Agilent 2100 Bioanalyzer using Agilent High Sensitivity DNA kit (Agilent Technologies). The libraries were sequenced on Illumina NextSeq500 with 75 bp single-end. Raw reads were trimmed using Cutadapt ${ }^{80}$ to remove adapters and minimum read length after trimming was set to 18 . Trimmed reads were mapped to hg38 using STAR aligner $^{81}$ (version 2.5.1a). Uniquely mapped reads were counted towards genes using featureCounts ${ }^{82}$ (version 1.5.1). Differential expression analysis was performed with DESeq2 (ref. ${ }^{83}$ ) using FDR $<0.01$. Heatmaps were generated using pheatmap package in R with default settings and relative expression as RPM calculated by $Z$-score scaling. GO-term analysis was carried out using PANTHER ${ }^{84}$ (http://pantherdb.org/about.jsp, version 14.1) using Fischer's exact test with FDR multiple test correction. Only genes differentially expressed between Senescence and Senescence MIR31HG-KD and $\mid \log _{2}$ fold-change $\mid>0.75$ were used for GOterm analysis.

MIR31HG oligonucleotide-based pull down. Cells were grown in 150 and 500 $\mathrm{cm}^{2}$ dishes in 25 or $90 \mathrm{ml}$ media, respectively, up to $\sim 90 \%$ confluency. Prior to collection cell were irradiated with UV light at $254 \mathrm{~nm}$, then scraped in ice-cold PBS, spun down at $800 \times g$ for $5 \mathrm{~min}$ at $4^{\circ} \mathrm{C}$ and stored at $-80^{\circ} \mathrm{C}$. Amino-C12LNA-containing oligonucleotides against $M I R 31 H G$ and luciferase (five per target, Exiqon, custom design, Supplementary Table 1) were coupled to Dynabeads MyOne Carboxylic Acid (Thermo Fisher Scientific) according to the manufacturer's instructions using $1.5 \mathrm{nmol}$ oligo per $100 \mu \mathrm{l}$ beads. Prior to use, the coated beads were blocked in RNA pulldown (RP) buffer $(50 \mathrm{mM}$ Tris/HCl $\mathrm{pH} 7.5$, $5 \mathrm{mM}$ EDTA, $500 \mathrm{mM} \mathrm{LiCl}, 0.5 \%$ DDM, 0.2\% SDS, $0.1 \%$ Na-deoxycholate, $4 \mathrm{M}$ Urea, 2.5 M TCEP, protease inhibitors (Roche)) with addition of ssDNA $(200 \mu \mathrm{g} /$ $\mathrm{ml})$ and BSA $(1 \mathrm{mg} / \mathrm{ml})$ and yeast RNA $(200 \mu \mathrm{g} / \mathrm{ml})$. In all, $0.5 \mathrm{~g}$ cell pellet was used per condition and resuspended in $5 \mathrm{ml}$ volume of RP buffer with murine RNase inhibitor (NEB, 1:500). Lysates were sonicated in $15 \mathrm{ml}$ tubes with Branson tip sonicator $(2 \times 10 \mathrm{sek}$, with $30 \mathrm{sek}$ break, at setting $15 \%)$ and clarified at $16,000 \times g$ for $5 \mathrm{~min}$ at $4{ }^{\circ} \mathrm{C}$. Supernatants were transferred to $2 \mathrm{ml}$ tubes and pre-heated to $65^{\circ} \mathrm{C}$ with shaking, then oligonucleotide-coated beads were added to lysates for $4 \mathrm{~h}$ incubation at $65^{\circ} \mathrm{C}$ with shaking $(250 \mu \mathrm{l}$ beads $/ 0.5 \mathrm{~g}$ initial cell pellet distributed in $2 \mathrm{ml}$ tubes). The beads were washed four times with RP buffer at room temperature and then washed with $1 \mathrm{ml} 50 \mathrm{mM}$ TEAB buffer to remove detergents. For mass spectrometry sample preparation the beads were resuspended in $100 \mu \mathrm{l} 50 \mathrm{mM}$ TEAB buffer (Sigma) including $2 \mathrm{mM}$ DTT. Trypsin was added (500 ng) for O/N incubation at $37^{\circ} \mathrm{C}$, then followed by treatments with DTT $(10 \mathrm{mM})$ and IAA (55 $\mathrm{mM}$ ) and acidification with TFA. One hundred microlitres StageTips (Thermo Fisher Scientific) were used for desalting and purified peptides were subjected to LC-MS analysis (as described in the above section).

Samples were analysed using instrument settings described above, and the obtained data were analysed with MaxQuant v. 1.5.2.8, using N-terminal acetylation and methionine oxidation as variable modifications. Fold change values of median peptide intensities were calculated for five replicates, and missing values were imputed using minimal intensity value detected in the analysis. Significantly enriched proteins in MIR31HG pulldown samples over control pulldown were selected based on $p$ value $<0.05$, signal intensity (fold enrichment over luciferase control) and number of unique peptides present in majority of replicates.

Polysome profiling. Prior to harvesting, cells were treated with $100 \mu \mathrm{g} / \mathrm{ml}$ cycloheximide (Sigma-Aldrich) for $3 \mathrm{~min}$. Cells were washed and scrapped off in icecold PBS containing $100 \mu \mathrm{g} / \mathrm{ml}$ cycloheximide. Cell were lysed in excess of polysome lysis buffer $(20 \mathrm{mM}$ Tris- $\mathrm{HCl}, 150 \mathrm{mM} \mathrm{KCl}, 5 \mathrm{mM} \mathrm{MgCl} 2,0.5 \% \mathrm{NP} 40$ (Igepal CA-630, Sigma-Aldrich), $2 \mathrm{mM}$ DTT, $100 \mu \mathrm{g} / \mathrm{ml}$ cycloheximide, Roche EDTA-free Protease Inhibitor (Roche) and murine RNase inhibitor (NEB)) and incubated while rotating for $10 \mathrm{~min}$ at $4{ }^{\circ} \mathrm{C}$. Debris, nuclei and mitochondria were cleared by centrifugation at $12,000 \times g$ for $15 \mathrm{~min}$ at $4{ }^{\circ} \mathrm{C}$. Lysate material was normalized to equal $A_{260}$ value measured on NanoDrop. Normalized lysate, $400 \mu \mathrm{l}$ total, was loaded on top of a $7-47 \%(\mathrm{w} / \mathrm{v})$ linear sucrose gradient (Sigma) in open top polyallomer tubes (Seton Scientific) and centrifuged at $38,000 \times g$ for $2.5 \mathrm{~h}$ at $4{ }^{\circ} \mathrm{C}$ using a Beckman ultracentrifuge (Optima L-90K, Class S) with the SW40ti rotor head (Beckman). Following ultracentrifugation, gradients were fractionated by piercing the tube bottom (Brandel Piercer), pushing gradient with $60 \%$ sucrose solution at a pace of $1 \mathrm{ml} / \mathrm{min}$ while continuously measuring $A_{260}$ using the BioLogicP system (Bio-Rad). RNA was subsequently extracted from each fraction by QIAzol (Qiagen) and chloroform extraction. Prior to RNA extraction, $20 \mathrm{pg}$ of firefly-luciferase in vitro-transcribed RNA was spiked into each fraction to control for potential loss of material in extraction protocol.

Nascent protein labelling biotin pull-down/western blot analysis. BJ-ER:BRAF cells $72 \mathrm{~h}$ were transfected using control or MIR31HG siRNAs and treated with $1 \mu \mathrm{M} 4$-OHT for $72 \mathrm{~h}$. Cell were starved in methionine-free medium for $1 \mathrm{~h}$. Subsequently, proteins were labelled with $50 \mu \mathrm{M}$ Click-iT AHA in methionine-free medium for $4 \mathrm{~h}$ prior to harvesting. Click-iT Protein Reaction Buffer Kit (Thermo Fisher Scientific) and biotin alkyne (Thermo Fisher Scientific) were used to label protein according to the manufacturer. Cell pellets were resuspended in $300 \mu \mathrm{l}$ of lysis buffer $(50 \mathrm{mM}$ Tris- $\mathrm{HCl} \mathrm{pH} \mathrm{8.0,1 \%} \mathrm{SDS)} \mathrm{in} \mathrm{the} \mathrm{presence} \mathrm{of} \mathrm{protease} \mathrm{inhi-}$ bitors (Roche) and incubated $10 \mathrm{~min}$ on ice. Cell lysates were sonicated using Branson sonicator $\left(3 \times 10 \mathrm{~s}, 10 \%\right.$ amplitude) and centrifuged at $15,000 \times g$, at $4{ }^{\circ} \mathrm{C}$ for $10 \mathrm{~min}$. At least $200 \mu \mathrm{g}$ of total protein was labelled and precipitated according to the manufacturer. Three labelling reactions were carried out for each sample to increase the final outcome. Proteins were resuspended in $50 \mu$ lysis buffer by shaking for $10 \mathrm{~min}$ at $30^{\circ} \mathrm{C}$ in the presence of protease inhibitors, and three labelling reactions were pooled. Sample volumes were adjusted to $1 \mathrm{ml}$ with Tris$\mathrm{HCl} \mathrm{pH} 8.0$ (final conc. $50 \mathrm{mM}$ Tris- $\mathrm{HCl}, 0.1 \%$ SDS), incubated for $10 \mathrm{~min}$ at $30^{\circ} \mathrm{C}$ and centrifuged at $15,000 \times g$ at $25^{\circ} \mathrm{C}$ for $5 \mathrm{~min}$ to remove undissolved material. Supernatants were incubated with $100 \mu \mathrm{l}$ of Dynabeads ${ }^{\mathrm{mw}}$ MyOne $^{\mathrm{mw}}$ Streptavidin T1 beads on a wheel rotator for $60 \mathrm{~min}$ at room temperature. After five washes with $1 \mathrm{ml}$ of $50 \mathrm{mM}$ Tris-HCl/0.1\% SDS buffer proteins were eluted in $1.5 \times$ NuPAGE SDS sample buffer containing $20 \mathrm{mM}$ DTT and analysed by western blot.

MIR31HG constructs for in vitro transcription. pGEM-MIR31HG plasmid was established by PCR amplification of MIR31HG sequence (NR_027054.2) from cDNA using primers listed in Supplementary Table 1 and cloned using TA cloning strategy with pGEM-T easy vector system kit (Promega), according to the manufacturer's protocols. MIR31HG truncations were established by PCR amplification from pGEM-MIR31HG plasmid with primers indicated in Supplementary Table 1 and cloned with In-fusion HD cloning kit (Clontech).

In vitro transcription and labelling. pGEM-MIR31HG WT and truncation constructs were linearized with $M l u \mathrm{I}$ restriction enzyme. For ND4 negative control the sequence was amplified from cDNA using T7 promoter included in the forward primer sequence (Supplementary Table 1).

The in vitro transcription reaction was performed by using $1 \mu \mathrm{g}$ of the linearized plasmid or PCR product together with $1 \times$ T7 RNA polymerase buffer, $1 \mathrm{mM}$ of NTPs), $1 \mathrm{U} / \mu \mathrm{l}$ of RNase inhibitors murine, and $2 \mathrm{U} / \mu \mathrm{l}$ of T7 RNA polymerase in a total volume of $20 \mu \mathrm{l}$ for $2 \mathrm{~h}$ at $37^{\circ} \mathrm{C}$

After 30 min DNAse treatment with TURBO DNA free at $37^{\circ} \mathrm{C}$ the reactions were stopped by adding $0.5 \mathrm{mM}$ EDTA. Samples were mixed with formamide loading buffer and boiled $1 \mathrm{~min}$ at $95^{\circ} \mathrm{C}$ before running on $1 \%$ agarose gel in $1 \times$ TBE. The RNA products were purified using NucleoSpin Gel and PCR Clean-up kit (Macherey-Nagel) with NTC buffer for RNA extraction. RNAs were dephosphorylated with $1 \mathrm{U}$ of Calf Intestine Alkaline Phosphatase (Invitrogen) and $5^{\prime}$-end labelled with T4 Polynucleotide Kinase (NEB) and $\gamma$-32P (Perkin Elmer). Labelled RNAs were precipitated following phenol:chloroform extraction. Radiolabelled RNAs were checked on agarose gel in $1 \times$ TBE buffer and quantified.

Electrophoretic mobility shift assay. Final concentration $2 \mathrm{nM}$ of radiolabelled RNA was adjusted to $5 \mathrm{ml}$ with Milli-Q water, incubated $1 \mathrm{~min}$ at $95^{\circ} \mathrm{C}$ and cooled on ice for $2 \mathrm{~min}$. RNA was allowed to fold for $30 \mathrm{~min}$ at $37^{\circ} \mathrm{C}$ in binding buffer (mM Tris- $\mathrm{HCl} \mathrm{pH} \mathrm{7.5,} 50 \mathrm{mM} \mathrm{KCl}, 5 \mathrm{mM} \mathrm{MgCl}, 0.1 \mathrm{mM} \mathrm{CaCl}, 1 \mathrm{mM}$ DTT, $0.1 \mathrm{mg} / \mathrm{ml} \mathrm{BSA}, 0.4 \mathrm{mg} / \mathrm{ml}$ fragmented yeast RNA (Sigma), $5 \%$ glycerol, $0.025 \%$ bromophenol blue and $0.025 \%$ xylene cyanol). Recombinant YBX1 (Abcam) was added at the concentrations indicated and the binding reaction was carried out at $30^{\circ} \mathrm{C}$ for $30 \mathrm{~min}$. Samples were loaded on a non-denaturing $0.7 \%$ agarose gel in cold $1 \times$ TBE buffer. After $2 \mathrm{~h}$ at $120 \mathrm{~V}$ of gel electrophoresis, the gels were vacuum dried for $90 \mathrm{~min}$ at $80^{\circ} \mathrm{C}$ and exposed to an Amersham Hyperfilm ECL film.

Luciferase reporter assays. The $3^{\prime}$ UTR of IL1A was amplified by PCR from cDNA (see primer list) and cloned into the pGL3-promoter Firefly luciferase reporter (Promega) using XbaI restriction enzyme (primer sequences are shown in Supplementary Table 1). In total, 40,000 YBX1-GFP cells were reverse transfected with siRNAs against endogenous YBX1 in a 24-well plate. After $24 \mathrm{~h}$ the cells were transfected using Lipofectamine 3000 (Lifetechnologies) with $500 \mathrm{ng}$ of the PGL3promoter or PGL-3_IL1A-3'UTR together with 150 ng of pRL-Tk Renilla luciferase reporter vector for transfection control and luciferase assay normalization. Twentyfour hours after transfection fresh media containing $1 \mu \mathrm{M}$ 4-OHT was added to the cells. Forty-eight hours after treatment Firefly and Renilla luciferase units were 
measured using the Dual-Glo Luciferase Assay System (Promega) and the Glo-Max multi-detection system with Instinct software v3.1.1 (Promega).

For the translocation of NF- $\mathrm{kB}$ to the nucleus, $500 \mathrm{ng}$ of a luciferase reporter plasmid containing four NF- $\mathrm{kB}$-binding sites (Addgene Plasmid \#111216) was transfected using Lipofectamine 3000 (Lifetechnologies) in BJ:ER:BRAF cells $24 \mathrm{~h}$ after siRNA transfection (control or siMIR31HG1-2). One hundred and fifty nanograms of pRL-Tk Renilla luciferase reporter vector was co-transfected as control and luciferase assay normalization. Twenty-four hours after transfection fresh media containing $1 \mu \mathrm{M} 4$-OHT was added to the cells. Forty-eight hours after treatment Firefly and Renilla luciferase units were measured using the Dual-Glo Luciferase Assay System and the Glo-Max multi-detection system with Instinct software v3.1.1(Promega).

Proximity ligation assay. Cells were reverse transfected and seeded in eight-well multichamber slides (Nunc Lab-Tek II Chamber Slide" system). Twenty-four hours later media was changed and $1 \mu \mathrm{M} 4$-OHT was added to the corresponding wells. After $72 \mathrm{~h}$ cells were fixed in $4 \%$ formaldehyde for $15 \mathrm{~min}$ and processed for PLA using Duolink ${ }^{\text {nt }}$ In Situ PLA ${ }^{\circledast}$ Probe Anti-Rabbit PLUS (Sigma) according to the manufacturer's instructions. The antibodies are listed in Supplementary Table 2. Images were obtained using a fluorescence microscope (Zeiss) and ZenPro software 2011 and quantified using Cell Profiler software v3.1.5. Five to 10 images were quantified from four independent experiments.

In vitro kinase assay. One microgram of recombinant YBX1 (Abcam) was incubated with $20 \mathrm{ng}$ of recombinant RSK1 protein (R\&D) and the corresponding in vitro-transcribed RNA in kinase buffer $(25 \mathrm{mM}$ TRIS/HCl, pH 7.5, $5 \mathrm{mM}$ glycerolphosphate, $2 \mathrm{mM}$ DTT, $10 \mathrm{mM} \mathrm{MgCl} 2,50 \mu \mathrm{M}$ ATP, $10 \mu \mathrm{Ci} \gamma$-32P (Perkin Elmer), protease inhibitor mixture Complete (Roche), phosSTOP (Roche)) for $15 \mathrm{~min}$ at $30^{\circ} \mathrm{C}$. Laemmli buffer was added to stop the reaction and boiled at $95^{\circ} \mathrm{C}$ for $5 \mathrm{~min}$. Proteins were separated by electrophoresis in 4-12\% NuPAGE Bis-Tris gels (Invitrogen). Subsequently, the gel was dried at $80^{\circ} \mathrm{C}$ for $1 \mathrm{~h}$ and then exposed to an Amersham Hyperfilm ECL film. The band intensities were measured using ImageJ/Fiji software v2.0.0.

Formaldehyde crosslinked RNA immunoprecipitation. Cells were seeded in $15 \mathrm{~cm}$ plates and treated with $1 \mu \mathrm{M} 4-\mathrm{OHT}$ the day after for $48 \mathrm{~h}$. The cells were washed twice with PBS and crosslinked with $1 \%$ formaldehyde in PBS shaking for $15 \mathrm{~min}$. Crosslinking was stopped incubating with glycine $0.25 \mathrm{M}$ for $5 \mathrm{~min}$. Eighty to $100 \mathrm{mg}$ of cell pellet was resuspended in lysis buffer $(50 \mathrm{mM}$ TRIS/HCl, $\mathrm{pH} 7.4$, $100 \mathrm{mM} \mathrm{NaCl}, 0.5 \%$ Triton X-100, $5 \mathrm{mM}$ EDTA, $0.25 \% \mathrm{Na}$-deoxycholate, Protease Inhibitor (Roche), RNase Inhibitor (NEB)) and sonicated three cycles of $10 \mathrm{~s}$ using a BRANSON sonicator at setting $15 \%$. After $15 \mathrm{~min}$ centrifugation at $16,000 \times g$ the supernatant was collected in a new tube. Ten per cent of the extract was saved as RNA input. The rest of the cell extract was incubated with $10 \mu$ of GFP-Trap ${ }^{\circ}$ Magnetic Agarose beads (Chromotek) rotating at $4{ }^{\circ} \mathrm{C}$ for $2 \mathrm{~h}$. The beads were then collected using a magnetic rack and washed once with lysis buffer and five times with high-salt buffer (50 mM TRIS/HCl pH 7.4, $1 \mathrm{M} \mathrm{NaCl}$, 0.5\% Triton X-100, $1 \mathrm{M}$ Urea, $5 \mathrm{mM}$ EDTA, $1 \mathrm{mM}$ DTT). After the last wash, the beads were resuspended in $100 \mu$ of RIP buffer (50 mM HEPES pH 7.5, $0.1 \mathrm{M} \mathrm{NaCl}, 5 \mathrm{mM}$ EDTA, $10 \mathrm{mM}$ DTT, $0.5 \%$ Triton X-100, $1 \%$ SDS) and incubated $45 \mathrm{~min}$ at $70^{\circ} \mathrm{C}$ to revert crosslinking. Proteins were digested incubating for $20 \mathrm{~min}$ at $37^{\circ} \mathrm{C}$ with $10 \mu \mathrm{l}$ proteinase K (Invitrogen, Thermo Fisher). RNA was extracted adding $600 \mu \mathrm{l}$ of TRIzol reagent (Invitrogen, Thermo Fisher) using the manufacturer's protocol.

Native RNA immunoprecipitation. Cells were seeded in $15 \mathrm{~cm}$ plates and treated with $1 \mu \mathrm{M} 4$-OHT the day after for $48 \mathrm{~h}$. The cells were washed twice with PBS and centrifuged at $500 \times g$ for $5 \mathrm{~min}$. The pellet was resuspended in lysis buffer $(50 \mathrm{mM}$ TRIS/HCl, pH 7.4, $100 \mathrm{mM} \mathrm{NaCl}, 0.5 \%$ Triton X-100, 5 mM EDTA, $0.25 \% \mathrm{Na}-$ deoxycholate, Protease Inhibitor (Roche), RNase Inhibitor (NEB)). Ten per cent of the extract was saved as RNA input. The rest of the cell extract was incubated with $10 \mu \mathrm{l}$ of GFP-Trap Magnetic Agarose beads (Chromotek) rotating at $4^{\circ} \mathrm{C}$ for $2 \mathrm{~h}$. The beads were then collected using a magnetic rack and washed three times with lysis buffer. RNA was extracted adding $600 \mu \mathrm{l}$ of TRIzol reagent (Invitrogen, Thermo Fisher) to the beads using the manufacturer's protocol.

Reporting summary. Further information on research design is available in the Nature Research Reporting Summary linked to this article.

\section{Data availability}

The MS data associated with this study has been deposited to PRIDE ProteomeXchange: PXD017475. RNA-seq data have been deposited in GEO with the accession number: GSE144752. Publicly available data was downloaded from UCSC Xena platform: https:// xenabrowser.net/datapages/?dataset=tcga_RSEM gene_fpkm\&host=https $\% 3 \mathrm{~A} \% 2 \mathrm{~F} \%$ 2Ftoil.xenahubs.net\&removeHub=https\%3A\%2F\%2Fxena.treehouse.gi.ucsc.edu\%3A443. https://xenabrowser.net/datapages/?dataset $=$ mc3.v0.2.8.PUBLIC.nonsilentGene. xena\&host=https\%3A\%2F\%2Fpancanatlas.xenahubs.net\&removeHub=https\%3A\%2F\% 2Fxena.treehouse.gi.ucsc.edu\%3A443. The data and reagents that support the findings of this study are available from the corresponding author upon reasonable request. Source data are available online for Figs. 1-6 and Supplementary Figs. 1-6.

\section{Code availability}

All the codes used in this study are available upon request to the corresponding authors.

Received: 2 June 2020; Accepted: 29 March 2021;

Published online: 28 April 2021

\section{References}

1. Hayflick, L. The limited in vitro lifetime of human diploid cell strains. Exp. Cell Res. 37, 614-636 (1965)

2. Kuilman, T., Michaloglou, C., Mooi, W. J. \& Peeper, D. S. The essence of senescence. Genes Dev. 24, 2463-2479 (2010).

3. Munoz-Espin, D. et al. Programmed cell senescence during mammalian embryonic development. Cell 155, 1104-1118 (2013).

4. Storer, M. et al. Senescence is a developmental mechanism that contributes to embryonic growth and patterning. Cell 155, 1119-1130 (2013)

5. Serrano, M., Lin, A. W., McCurrach, M. E., Beach, D. \& Lowe, S. W. Oncogenic ras provokes premature cell senescence associated with accumulation of p53 and p16INK4a. Cell 88, 593-602 (1997).

6. Michaloglou, C. et al. BRAFE600-associated senescence-like cell cycle arrest of human naevi. Nature 436, 720-724 (2005).

7. Braig, M. et al. Oncogene-induced senescence as an initial barrier in lymphoma development. Nature 436, 660-665 (2005)

8. Chen, Z. et al. Crucial role of p53-dependent cellular senescence in suppression of Pten-deficient tumorigenesis. Nature 436, 725-730 (2005).

9. Daniotti, M. et al. BRAF alterations are associated with complex mutational profiles in malignant melanoma. Oncogene 23, 5968-5977 (2004).

10. Coppe, J. P. et al. Senescence-associated secretory phenotypes reveal cellnonautonomous functions of oncogenic RAS and the p53 tumor suppressor. PLoS Biol. 6, 2853-2868 (2008)

11. Kuilman, T. et al. Oncogene-induced senescence relayed by an interleukindependent inflammatory network. Cell 133, 1019-1031 (2008).

12. Acosta, J. C. et al. A complex secretory program orchestrated by the inflammasome controls paracrine senescence. Nat. Cell Biol. 15, 978-990 (2013).

13. Coppe, J. P., Desprez, P. Y., Krtolica, A. \& Campisi, J. The senescenceassociated secretory phenotype: the dark side of tumor suppression. Annu. Rev. Pathol. 5, 99-118 (2010).

14. Salama, R., Sadaie, M., Hoare, M. \& Narita, M. Cellular senescence and its effector programs. Genes Dev. 28, 99-114 (2014).

15. Demaria, M. et al. An essential role for senescent cells in optimal wound healing through secretion of PDGF-AA. Dev. Cell 31, 722-733 (2014).

16. Xue, W. et al. Senescence and tumour clearance is triggered by p 53 restoration in murine liver carcinomas. Nature 445, 656-660 (2007).

17. Iannello, A., Thompson, T. W., Ardolino, M., Lowe, S. W. \& Raulet, D. H. p53-dependent chemokine production by senescent tumor cells supports NKG2D-dependent tumor elimination by natural killer cells. J. Exp. Med. 210 2057-2069 (2013)

18. Krtolica, A., Parrinello, S., Lockett, S., Desprez, P. Y. \& Campisi, J. Senescent fibroblasts promote epithelial cell growth and tumorigenesis: a link between cancer and aging. Proc. Natl Acad. Sci. USA 98, 12072-12077 (2001).

19. Jeyapalan, J. C., Ferreira, M., Sedivy, J. M. \& Herbig, U. Accumulation of senescent cells in mitotic tissue of aging primates. Mech. Ageing Dev. 128 36-44 (2007).

20. Baker, D. J. et al. Clearance of p16Ink4a-positive senescent cells delays ageingassociated disorders. Nature 479, 232-236 (2011).

21. Hernandez-Segura, A. et al. Unmasking transcriptional heterogeneity in senescent cells. Curr. Biol. 27, 2652-2660 e2654 (2017).

22. Casella, G. et al. Transcriptome signature of cellular senescence. Nucleic Acids Res. 47, 7294-7305 (2019).

23. Wang, Z. et al. Telomeric repeat-containing RNA (TERRA) constitutes a nucleoprotein component of extracellular inflammatory exosomes. Proc. Natl Acad. Sci. USA 112, E6293-6300 (2015).

24. Ozes, A. R. et al. NF-kappaB-HOTAIR axis links DNA damage response, chemoresistance and cellular senescence in ovarian cancer. Oncogene 35 5350-5361 (2016).

25. Rapicavoli, N. A. et al. A mammalian pseudogene lncRNA at the interface of inflammation and anti-inflammatory therapeutics. Elife 2, e00762 (2013).

26. Jin, C. et al. Inhibition of lncRNA MIR31HG promotes osteogenic differentiation of human adipose-derived. Stem Cells Stem Cells 34, 2707-2720 (2016). 
27. Montes, M. \& Lund, A. H. Emerging roles of lncRNAs in senescence. FEBS J. 283, 2414-2426 (2016)

28. Montes, M. et al. The IncRNA MIR31HG regulates p16(INK4A) expression to modulate senescence. Nat. Commun. 6, 6967 (2015).

29. Li, L. et al. LncRNA-OIS1 regulates DPP4 activation to modulate senescence induced by RAS. Nucleic Acids Res. 46, 4213-4227 (2018).

30. Pritchard, C. A., Samuels, M. L., Bosch, E. \& McMahon, M. Conditionally oncogenic forms of the A-Raf and B-Raf protein kinases display different biological and biochemical properties in NIH 3T3 cells. Mol. Cell Biol. 15, 6430-6442 (1995).

31. Fischer, M. Census and evaluation of p53 target genes. Oncogene 36, 3943-3956 (2017).

32. Acosta, J. C. et al. Chemokine signaling via the CXCR2 receptor reinforces senescence. Cell 133, 1006-1018 (2008)

33. Chien, Y. et al. Control of the senescence-associated secretory phenotype by NF-kappaB promotes senescence and enhances chemosensitivity. Genes Dev. 25, 2125-2136 (2011).

34. Orjalo, A. V., Bhaumik, D., Gengler, B. K., Scott, G. K. \& Campisi, J. Cell surface-bound IL-1alpha is an upstream regulator of the senescence-associated IL-6/IL-8 cytokine network. Proc. Natl Acad. Sci. USA 106, 17031-17036 (2009).

35. Laberge, R. M. et al. MTOR regulates the pro-tumorigenic senescenceassociated secretory phenotype by promoting IL1A translation. Nat. Cell Biol. 17, 1049-1061 (2015).

36. Georgilis, A. et al. PTBP1-mediated alternative splicing regulates the inflammatory secretome and the pro-tumorigenic effects of senescent cells. Cancer Cell 34, 85-102 e109 (2018).

37. Lyabin, D. N., Eliseeva, I. A. \& Ovchinnikov, L. P. YB-1 protein: functions and regulation. Wiley Interdiscip. Rev. RNA 5, 95-110 (2014).

38. Kwon, E. et al. The RNA-binding protein YBX1 regulates epidermal progenitors at a posttranscriptional level. Nat. Commun. 9, 1734 (2018).

39. Skabkina, O. V., Lyabin, D. N., Skabkin, M. A. \& Ovchinnikov, L. P. YB-1 autoregulates translation of its own mRNA at or prior to the step of $40 \mathrm{~S}$ ribosomal subunit joining. Mol. Cell Biol. 25, 3317-3323 (2005).

40. Matsumoto, S. et al. Ribonucleoprotein Y-box-binding protein-1 regulates mitochondrial oxidative phosphorylation (OXPHOS) protein expression after serum stimulation through binding to OXPHOS mRNA. Biochem. J. 443 573-584 (2012).

41. Goodarzi, H. et al. Endogenous tRNA-derived fragments suppress breast cancer progression via YBX1 displacement. Cell 161, 790-802 (2015).

42. Wu, S. L. et al. Genome-wide analysis of YB-1-RNA interactions reveals a novel role of YB-1 in miRNA processing in glioblastoma multiforme. Nucleic Acids Res. 43, 8516-8528 (2015).

43. Yang, Y. et al. RNA 5-methylcytosine facilitates the maternal-to-zygotic transition by preventing maternal mRNA decay. Mol. Cell 75, 1188-1202 e1111 (2019).

44. Evdokimova, V. et al. The major mRNA-associated protein YB-1 is a potent 5 cap-dependent mRNA stabilizer. EMBO J. 20, 5491-5502 (2001).

45. Prabhu, L. et al. Role of post-translational modification of the $\mathrm{Y}$ box binding protein 1 in human cancers. Genes Dis. 2, 240-246 (2015).

46. Evdokimova, V. et al. Akt-mediated YB-1 phosphorylation activates translation of silent mRNA species. Mol. Cell Biol. 26, 277-292 (2006).

47. Stratford, A. L. et al. Y-box binding protein-1 serine 102 is a downstream target of p90 ribosomal S6 kinase in basal-like breast cancer cells. Breast Cancer Res. 10, R99 (2008).

48. Sutherland, B. W. et al. Akt phosphorylates the Y-box binding protein 1 at Ser102 located in the cold shock domain and affects the anchorageindependent growth of breast cancer cells. Oncogene 24, 4281-4292 (2005).

49. El-Naggar, A. M. et al. Translational activation of HIF1alpha by YB-1 promotes sarcoma metastasis. Cancer Cell 27, 682-697 (2015).

50. Evdokimova, V. et al. Translational activation of snaill and other developmentally regulated transcription factors by YB-1 promotes an epithelial-mesenchymal transition. Cancer Cell 15, 402-415 (2009).

51. Roux, P. P., Richards, S. A. \& Blenis, J. Phosphorylation of p90 ribosomal S6 kinase (RSK) regulates extracellular signal-regulated kinase docking and RSK activity. Mol. Cell Biol. 23, 4796-4804 (2003).

52. Ventura, A. et al. Restoration of $\mathrm{p} 53$ function leads to tumour regression in vivo. Nature 445, 661-665 (2007)

53. $\mathrm{Wu}, \mathrm{C}$. H. et al. Cellular senescence is an important mechanism of tumor regression upon c-Myc inactivation. Proc. Natl Acad. Sci. USA 104, 13028-13033 (2007)

54. Farr, J. N. et al. Targeting cellular senescence prevents age-related bone loss in mice. Nat. Med. 23, 1072-1079 (2017).

55. Xu, M. et al. Targeting senescent cells enhances adipogenesis and metabolic function in old age. Elife 4, e12997 (2015).

56. Freund, A., Patil, C. K. \& Campisi, J. p38MAPK is a novel DNA damage response-independent regulator of the senescence-associated secretory phenotype. EMBO J. 30, 1536-1548 (2011).
57. Herranz, N. et al. mTOR regulates MAPKAPK2 translation to control the senescence-associated secretory phenotype. Nat. Cell Biol. 17, 1205-1217 (2015).

58. Kang, C. et al. The DNA damage response induces inflammation and senescence by inhibiting autophagy of GATA4. Science 349, aaa5612 (2015)

59. Tasdemir, N. et al. BRD4 connects enhancer remodeling to senescence immune surveillance. Cancer Discov. 6, 612-629 (2016).

60. Hoare, M. et al. NOTCH1 mediates a switch between two distinct secretomes during senescence. Nat. Cell Biol. 18, 979-992 (2016).

61. Davies, H. et al. Mutations of the BRAF gene in human cancer. Nature 417, 949-954 (2002).

62. Beiter, T. et al. Exercise, skeletal muscle and inflammation: ARE-binding proteins as key regulators in inflammatory and adaptive networks. Exerc. Immunol. Rev. 21, 42-57 (2015)

63. Dominguez, D. et al. Sequence, structure, and context preferences of human RNA binding proteins. Mol. cell 70, 854-867 e859 (2018).

64. Nekrasov, M. P. et al. The mRNA-binding protein YB-1 (p50) prevents association of the eukaryotic initiation factor eIF4G with mRNA and inhibits protein synthesis at the initiation stage. J. Biol. Chem. 278, 13936-13943 (2003).

65. Schittek, B. et al. The increased expression of Y box-binding protein 1 in melanoma stimulates proliferation and tumor invasion, antagonizes apoptosis and enhances chemoresistance. Int J. Cancer 120, 2110-2118 (2007).

66. Castellana, B., Aasen, T., Moreno-Bueno, G., Dunn, S. E. \& Ramon y Cajal, S. Interplay between YB-1 and IL- 6 promotes the metastatic phenotype in breast cancer cells. Oncotarget 6, 38239-38256 (2015).

67. Proud, C. G. Phosphorylation and signal transduction pathways in translational control. Cold Spring Harb. Perspect. Biol. 11, a033050 (2019).

68. Martin, M. et al. Novel serine 176 phosphorylation of YBX1 activates NFkappaB in colon cancer. J. Biol. Chem. 292, 3433-3444 (2017).

69. Prabhu, L. et al. Critical role of phosphorylation of serine 165 of YBX1 on the activation of NF-kappaB in colon cancer. Oncotarget 6, 29396-29412 (2015).

70. Yoon, J. H. et al. Scaffold function of long non-coding RNA HOTAIR in protein ubiquitination. Nat. Commun. 4, 2939 (2013).

71. Wang, P. et al. The STAT3-binding long noncoding RNA lnc-DC controls human dendritic cell differentiation. Science 344, 310-313 (2014).

72. Lo Piccolo, L., Mochizuki, H. \& Nagai, Y. The lncRNA hsromega regulates arginine dimethylation of human FUS to cause its proteasomal degradation in Drosophila. J. Cell Sci. 132, https://doi.org/10.1242/jcs.236836 (2019).

73. $\mathrm{Li}, \mathrm{D}$. et al. Long noncoding RNA HULC modulates the phosphorylation of YB-1 through serving as a scaffold of extracellular signal-regulated kinase and YB-1 to enhance hepatocarcinogenesis. Hepatology 65, 1612-1627 (2017).

74. Eide, P. W., Eilertsen, I. A., Sveen, A. \& Lothe, R. A. Long noncoding RNA MIR31HG is a bona fide prognostic marker with colorectal cancer cellintrinsic properties. Int. J. Cancer 144, 2843-2853 (2019).

75. Shih, J. W. et al. Long noncoding RNA LncHIFCAR/MIR31HG is a HIF1alpha co-activator driving oral cancer progression. Nat. Commun. 8, 15874 (2017).

76. Yang, H. et al. Long noncoding RNA MIR31HG exhibits oncogenic property in pancreatic ductal adenocarcinoma and is negatively regulated by miR-193b. Oncogene 35, 3647-3657 (2016)

77. Goldman, M. et al. Visualizing and interpreting cancer genomics data via the Xena platform. Nat. Biotechnol. 38, 675-678 (2020).

78. Cox, J. \& Mann, M. MaxQuant enables high peptide identification rates, individualized p.p.b.-range mass accuracies and proteome-wide protein quantification. Nat. Biotechnol. 26, 1367-1372 (2008).

79. Wickham, H. ggplot2: Elegant Graphics for Data Analysis (Springer, 2016).

80. Martin, M. Cutadapt removes adapter sequences from high-throughput sequencing reads. EMBnet J. https://doi.org/10.14806/ej.17.1.200 (2011).

81. Dobin, A. et al. STAR: ultrafast universal RNA-seq aligner. Bioinformatics 29 , 15-21 (2013).

82. Liao, Y., Smyth, G. K. \& Shi, W. featureCounts: an efficient general purpose program for assigning sequence reads to genomic features. Bioinformatics $\mathbf{3 0}$, 923-930 (2014)

83. Love, M. I., Huber, W. \& Anders, S. Moderated estimation of fold change and dispersion for RNA-seq data with DESeq2. Genome Biol. 15, 550 (2014).

84. Thomas, P. D. et al. PANTHER: a library of protein families and subfamilies indexed by function. Genome Res. 13, 2129-2141 (2003).

\section{Acknowledgements}

We thank Morten Frodin for providing reagents and useful input for experiments We thank Janine Erler and Kristian Helin for providing cell lines. We thank the rest of the Lund lab for contributing with helpful discussions. The Lund lab is supported by grants from the Danish Council for Independent Research (Sapere Aude program); the Novo Nordisk Foundation; and the Lundbeck Foundation and the Danish Cancer Society. 


\section{Author contributions}

M.M. and A.H.L. designed the experiments and analysed the data. M.M. wrote the manuscript and all the coauthors gave comments and input. M.M., M.L., F.S.A., B.M., and S.T. conducted experiments. F.S.A. analysed the RNA-seq data. M.L. performed the mass spectrometry experiments and analysis with help from L.M.H. and J.S.A. N.R. and A.J.S. analysed MIR31HG expression in THCA and CRC from TCGA public available data.

\section{Competing interests}

The authors declare no competing interests.

\section{Additional information}

Supplementary information The online version contains supplementary material available at https://doi.org/10.1038/s41467-021-22746-4.

Correspondence and requests for materials should be addressed to M.M. or A.H.L.

Peer review information Nature Communications thanks Gerardo Ferbeyre, Hsueh-Fen Juan and the other, anonymous, reviewer(s) for their contribution to the peer review of this work. Peer reviewer reports are available.
Reprints and permission information is available at http://www.nature.com/reprints

Publisher's note Springer Nature remains neutral with regard to jurisdictional claims in published maps and institutional affiliations.

\section{(c) (i)}

Open Access This article is licensed under a Creative Commons Attribution 4.0 International License, which permits use, sharing, adaptation, distribution and reproduction in any medium or format, as long as you give appropriate credit to the original author(s) and the source, provide a link to the Creative Commons license, and indicate if changes were made. The images or other third party material in this article are included in the article's Creative Commons license, unless indicated otherwise in a credit line to the material. If material is not included in the article's Creative Commons license and your intended use is not permitted by statutory regulation or exceeds the permitted use, you will need to obtain permission directly from the copyright holder. To view a copy of this license, visit http://creativecommons.org/ licenses/by/4.0/.

(C) The Author(s) 2021 